\title{
Causal-morphologische Zellenstudien.
}

\author{
IV. Mitteilung:
}

\begin{abstract}
Die Explantation von Säugetiergeweben - ein der Regnlation von seiten des Organismus nicht unterworfenes Gestaltungsgeschehen.
\end{abstract}

Von

\author{
Prof. Dr. Albert Oppel, \\ Halle a. $\mathrm{S}$.
}

(Aus der Anatomischen Anstalt der Universität Halle a. S.)

Mit Tafel IX und $\mathrm{X}$.

Eingegangen am 10. November 1911.

\section{Experimenteller Teil.}

CARrel 1 ij hat vorgeschlagen, die Kultur der Gewebe von erwachsenen Säugetieren und vom Menschen 2) außerhalb des Organismus in Blutplasma oder -serum nach einer von ibm angegebenen Methode im Wärmeofen bei $37^{\circ} \mathrm{C}$. vorzunehmen. Auch verwandte er Ringersche Lösung mit oder ohne Zusatz von Bouillon oder Agar. Er berichtet ïher Erfolge mit fast allen Geweben, besonders werden

1) Carrel, Alexis, Die Kultur der Gewebe außerhalb des Organismas. Berliner klin. Wochenschr. Nr. 30. S. 1364-1367. 24. Juli 1911. Mit 10 Fig. Siehe dort die frühere Literatur.

2) Kulturversuche an embryonalen Geweben außerhalb des Organismus wurden von verschiedenen Seiten, besonders von Harrison, Burrows und Braus, mit Erfolg durchgefïhrt. Auch schon Rouxs Beobachtung der Anziehung und Selbstordnung isolierter Furchungszellen in filtriertem Hühnereiweiß (1893) gehört als erster bezüglicher causal-analytischer Versuch hierher. Einen beträchtlichen Teil dieser Literatur findet man in den Arbeiten dieser Forscher (besonders in den neueren Bänden des Journal of Experimental Zoology und des Archivs für Entwicklungsmechanik der Organismen) zusammengestellt, so daß ich auf eine Wiedergabe hier verzichten kann. um so mehr als der Inhalt mein heutiges Thema nicht unmittelbar beribrt. 
genannt: Milz, Peritoneum, Knorpel, Bindegewebe, Epithelgewebe (in Schilddriise, Niere, Haut), Leber, Sarcom und Carcinom; abgebildet werden Milz, Sarcom, Endotheliom und eine Ganglienzelle mit Achsencylinder.

Die Versuche des amerikanischen Autors, dessen glänzende Ergebnisse nach seinem in Berlin gehaltenen Vortrage und seiner Publikation in der Berliner klinischen Wochenschrift in jedermanns Munde sind, lassen sich nicht so ganz leicht mit Erfolg wiederholen. Es gehört dazu nicht nur ein mit, für direkte Beobachtung am Mikroskop eingerichteten Wärmeofen, elektrischer Centrifuge und andern Instrumenten ausgestattetes Laboratorium, welches zugleich ein Operieren unter aseptischen Kautelen gestattet, sondern auch für die Feststellung und Prüfung der Resultate Erfahrung in der modernen Mikrotechnik. So müßte derjenige, welcher mit der neuen Methode gute Erfolge zu erzielen wünscht, um die Ergebnisse in causalmorphologischer Hinsicht verwerten zu können, im Besitze eines solchen wohlausgerüsteten Laboratoriums sein und die Erfahrungen des Chirurgen, Bakteriologen und Histologen in sich vereinigen.

Bei der hohen Bedeutung, welche den Carresschen Ergebnissen in theoretischer und praktischer Hinsicht zukommt, wird es nicht ohne Interesse sein, zu erfahren, ob und wieweit sich dieselben von andrer Seite werden bestätigen lassen. Jeder Versuch, auf dem von Carrer vorgeschlagenen Wege wenigstens soweit zu gehen, als dies möglich ist, muß daher willkommen sein und ich möchte es nicht für wertlos erachten, dasjenige hier mitzuteilen, was ich selbst bei meinen, mit einfacheren Instrumenten und nur unter den in einem anatomischen Institut zu erreichenden nicht vollkommen aseptischen Verhältnissen, angestellten Experimenten von den CarReLschen Befunden bestätigen konnte und was ich denselben beifuigen möchte. Andre werden vielleicht andres bestätigen können und noch weiter fortschreiten.

Dank dem guitigen Entgegenkommen meines hochverehrten Lehrers Herrn Geh. Rat Roux, welcher mir die Mittel seines Institutes in vollstem Maße für diese Arbeit überließ, konnte ich für meine Experimente unter anderm eine treffliche neu beschaffte LeITzsche Handcentrifuge sowie einen die Temperatur sebr genaa regulierenden Strahlenbriter »Germania * von SARTORIUS verwenden. Ich untersuchte Material von zwei Kaninchen, einem Meerschweinchen, zwei neugeborenen und einem erwachsenen Hund, sowie vier Katzen. Ich legte kleinste. Organstiuckchen in Blutplasma, welches ich nach der Vorschrift 
von Carrel bereitete, zum Teil in Glasschalen, zum Teil auf Objektträger and Deckgläschen unter möglichster Beachtung aller von CARREL angegebenen Kautelen und beobachtete die Kulturen, nachdem sie verschiedene Zeit bei $37^{\circ} \mathrm{C}$. im Wärmeofen verbracht hatten, lebend an einem mit Wärmetisch versehenen Mikroskop und hernach an den vom fixierten Präparat hergestellten Schnitten.

In vielen Punkten war es mir freilich nicht möglich, die CARRELschen Ergebnisse bis heute schon zu bestätigen, so gelang es mir nicht, wahrseheinlich wegen Mangel der im Anatomischen Institut nur schwer zu erzielenden vollständigen Asepsis, die Kulturen so lange am Leben zu erhalten, wie dies CARReL möglich war, sie zu solcher Ausdehnung wachsen zu lassen, wie dies CARrel abbildet, oder gar Wundheilungen von Defekten in der Haut und ähnliches im Thermostat zu erzielen. Haut und Schleimhäute, wohl weil am wenigsten aseptisch, verdarben mir am raschesten, auch konnte ich in epithelialen Geweben Mitosen in meinen Präparaten überhaupt nicht häufiger finden, als sie in normalen Geweben vorzakommen pflegen. Auch der Mangel an Erfahrung mag zu Anfang manchen Mißerfolg bringen, doch ließ ich mich dadurch nicht entmatigen. Zuerst arbeitete ich an Kaninchen- and Meersehweinchenmaterial, welche mir zunächst zur Verfügung standen, resultatlos. Erst als ich zu Hunden und Katzen fortschritt, warden die Ergebnisse besser, und bei letzteren erzielte ich die Resultate, welche manche Befunde Carrels zu bestätigen, denselben auch Neues hinzuzufügen rermochten und anch als Unterstïtzung der Deutungen Carrels verwertet werden können.

Namentlich von solchen, welche mit Mißerfolg gearbeitet haben, wird der Verdacht kaum unterdrückt. werden können, daß aus den den Versuchstieren entnommenen Gewebs- und Organstickchen, nachdem dieselben in das Blutplasma ubertragen wurden, schon zur Zeit zu der das Blutplasma noch nicht geronnen ist, Gewebselemente (Zellen) austreten und sich im umgebenden Plasma ausbreiten und so Höfe um die Stuckchen entstehen lassen, welche im Auge des Beschauers wie auf der photographischen Platte Bilder hervorrufen, die mit den von Carrel nach Photographien wiedergegebenen und als Wachstumserscheinungen gedeuteten Figuren einige Ähnlichkeit besitzen. Auch besteht namentlich bei Organen von der Beschaffenheit, wie sie die von Carrel vielfach als Versuchs- und Demonstrationsobjekt bei seinen Abbildungen bentitzte Milz zeigt, wohl die Möglichkeit, daß auch in späterer Zeit noch Zellen ausgepreßt werden oder auswandern, so daß diese Höfe um die Organstückchen all- 
mählich wachsen. Ich habe daher, um jede Selbsttäuschung hinsichtlich der Beobachtung tatsächlicher Wachstnmserscheinungen zu vermeiden, weniger auf die von CARREL in seinen Abbildungen besonders betonten Veränderungen gelegt, welche das Präparat in seiner äußeren Gestalt zeigte, nachdem es in das Blutplasma in den Ofen eingelegt worden war. Wichtiger scheint mir der Nachweis des tatsächlichen Vorhandenseins von mitotischen Kernteilungsfiguren zu sein, welcher zur Zeit, als ich diese Arbeit begann und vollendete, von CARREL zwar erwähnt, aber im Bilde noch nicht erbracht war. Dieser Nachweis aber muß zunächst auf das energisehste, und zwar nicht nar an embryonalen Organen und Geweben, fur welche er von BuRrow 1) erbracht wurde, sondern auch fur das erwachsene Tier gefordert werden. Zweifellos wird von CARREL in seiner zu erwartenden ausfuhrlichen Arbeit vielleicht schon vor Erscheinen dieser Abhandlung meinem Wunsche Rechnung getragen werden. Aber auch in diesem Falle erscheinen die von mir und vielleicht von andern in nächster Zeit gebotenen Zellteilungsfiguren vom überlebenden Säugetiergewebe nicht überflüssig, da es bei der Wichtigkeit der ganzen Frage nicht unerwünscht sein dürfte, diesen Nachweis nicht nur von einer Seite gefuhrt zu sehen. Aus diesem Grunde gab ich auch meiner inzwischen erschienenen kurzgefaßten Mitteilung im Anatomischen Anzeiger ${ }^{2}$ ) einige Figuren bei, welche andern Stadien, als die bier gebotenen, entsprechen und so sich mit diesen wechselseitig ergänzen.

Ich habe daher mein Augenmerk besonders anf das Vorhandensein von Mitosen und, was mir besonders wichtig erscheint, anf das erste Auftreten, die Zahl, Anordnung, Verteilung und den Erhaltnngszustand derselben gerichtet und zu diesem Zweck die Organ- und Gewebsstïckchen aus dem Blutplasma in passenden Zwischenräumen (nach 2, 4, 5, 6, 7, 18, 24, 48 Stunden) in Fixierungsflitssigkeiten (besonders Zenkersche und Flemmingsche Flüssigkeit) eingelegt, in $\mathrm{Pa}$ raffin geschnitten und mit Hämatoxylin-Eosin bzw. Safranin gefärbt.

Dabei gelang es mir, an Material der Katze in zwei Organen, nämlich in der Milz und im Knochenmark, schon frühzeitig Mitosen

1) Burrows, Montrose, The growth of tissues of the chick embryo outside the animal body, with special reference to the nervous system. Joutn. of Exper. Zool. Vol. 10. No. 1. 1911. p. 63-83. - Die von Carrel erwähnte Arbeit von RUTH ist mit noch nicht zugänglich geworden.

2) OpPec, A., Über die Kultur ron Sängetiergeweben außerhalb des Organismus. Anat. Anz. Bd. 40. Hft. 17/18. S. 464-468. 1912. Mit 5 Figuren. 
nachzuweisen, und zwar, in einigen Präparaten, bereits um die 5. und 6. Stunde und später in größerer Anzahl als in frisch eingelegten Kontrollstiuckchen desselben Tieres.

Wir stehen damit vor der Frage, ob wir durch diese Befunde das wichtigste Resultat, welches uns CARREL mitgeteilt hat, für bestätigt halten dürfen. Dürfen wir demnach schon annehmen, daß dem Organismus entnommene Gewebsstiuckchen im Blutplasma nicht nur fortleben, sondern auch, was sich durch die beobachtete Zellvermehrung kund geben würde, wachsen können?

Um diese Frage ventilieren zu können, erscheint es zunächst erforderlich, die von mir nach meinen Präparaten wiedergegebenen Zeichnungen an der Hand der beigegebenen Tafeln durchzusehen.

In den Abbildungen gebe ich zunächst einige Stellen aus den Schnittpräparaten von Milz und Knochenmark wieder, welche das Aussehen und die Anordnung der Mitosen zeigen können. Fig. 1 ist ein Übersichtsbild vom Rande des eingelegten Milzstïckchen und weist etwa zehn Mitosen auf. Es läßt sich in Fig. 1 die Grenze des Stïckes gegen das mitgeschnittene Blutplasma deutlich erkennen, sie fällt fast zusammen mit der Grenze des das Stick nur wenig uberragenden dichter geronnenen Fibrins, das dann bald in das mehr locker geflochtene Netzwerk des Fibrins übergeht, welches das Stiick in breiter Strecke dicht umhüllt.

Ich erhielt den Eindruck, daß dieser Fibrinmantel bei tatsächlich lebend gebliebenen Stücken wenigstens in den Anfangsstadien stets deutlich zu sehen war. Verflissigte sich derselbe rasch, so folgte bald Fänlnis nach. Bei in reines Serum eingelegten Stucken, welches also des Fibrins bereits ermangelte, fehlte natürlich der Fibrinmantel. Doch ließen sich zwischen beiden Möglichkeiten verschiedene Zwischenstufen beschreiben, da das Fibrin, wie es sehon länger bekannt ist, bei der Gerinnung nicht auf einmal aus dem Plasma anstritt. Nach BRAUS 1) ist das Fibrin bei Dunkelfeldbeleuchtung schon im frischen Plasma als Gerüst nachweisbar. Vielmehr ist der Vorgang ein sich uiber längere Zeit erstreckender ganz allmählicher. So fand ich in Serum, aus welchem ich etwa 10 Minuten nach Beginn der Gerinnung einen dicken Fibrinpfropf entfernt hatte, nach weiteren 10 Minuten

1) Braus, H., Demonstration und Erläuterung von Deckglaskulturen lebender Embryonalzellen und -organe. Münch. med. Wochenschr. 1911. - Die Entstehnng der Nervenbahnen. Ges. Deutsch. Naturf. u. Ärzte. Verh. 1911. 
von neuem Fibringerinnsel, wenn anch nicht mehr so dicht. Wurde letzteres wieder entfernt, so zeigten nach weiteren 10 Minuten neuauftretende Fibrinflocken, daß der Vorgang der Gerinnung anch dann noch nicht beendigt war. Die besten Resultate für das Auftreten der Mitosen erhielt ich in solchem Plasma, bei welchem die Gerinnung vor dem Einlegen der Stiicke noch nicht begonnen hatte.

Wie das auch in der Zeichnung (s. Fig. 1, 2 und 4) wiedergegeben ist, verlaufen die Fäserchen des Fibrins nicht unregelmäßig, sondern in bestimmter Richtung. Ich erhielt den Eindruck, daB diese Richtung in Beziehung zu den im Plasma schwimmenden Körpern (Zellen usw.) steht. Fibrinfäden verbinden Zellen und Zellgruppen miteinander oft in gerader Linie, an andern Stellen umgreifen Fibrinfäden auch bogenförmig Zellen, z. B. Gruppen von roten Blatkörperchen. Die Mehrzahl der im Gesichtsfeld vorhandenen Fäden aber erscheint, weil von außerhalb des Gesichtsfeldes liegenden Gebilden ansgebend, mehr oder minder schräg durchschnitten, daher häufig als Punkt. Ich denke, daß diese Nebenbefunde der Literatur über das Fibrin, welche dem Pathologen besser bekannt sein wird, kaum etwas Neues hinzuzufügen vermögen. Von Wichtigkeit scheint die Kenntnis dieser Verhältnisse aber schon aus dem Grunde, weil CARrel erwähnt, daß die wachsenden Präparate den Nährboden weiterhin wieder $\mathrm{zu}$ verfliussigen vermögen. Zunächst erhielt ich nicht den Eindruck, daß es für das Wachstum besonders günstig ist, wenn eine solche Verfliissigung bald eintritt. Dies mag sich vielleicht in den späteren Epochen des Versuches, auf welche sich die Angaben Carrels beziehen, ändern.

Fig. 2, 3, 4, 5 zeigen dann Mitosen aus der Katzenmilz bei stärkerer Vergrößerung aus verschiedenen Zeiten des Versuches (2.--24. Stunde). Fig. 2 und 4 zeigen Zellen, welche, was in meinen Präparaten den selteneren Fall darstellt, ganz am Rande des eingelegten Stiickes lagen, besonders die in Fig. 4 wiedergegebene Zelle liegt ganz exponiert, fast freisehwimmend im Blutplasma. Fig. 3 und 5 gehören nicht unmittelbar den am Rande des Stiuckchens gelegenen Zellen an. Von Fig. 6, welche nicht aus Blutplasmaztichtungen stammt und sich von den Fig. 2--4 wesentlich unterscheidet, wird später die Rede sein. Die Fig. 3 und 5, welche den Typen des Monasters und Dyasters entsprechen, zeigen, daß die beobachteten Mitosen den verschiedensten in der Regel bei der Caryokinese vorkommenden Formen entsprechen. 
Vom Knochenmark gebe ich zunächst in Fig. 7 ein Übersichtsbild, welches vom Rande des eingelegten Stückchen entstammt. Auch hier ist rechts vom Beschauer der Fibrinmantel mitgezeichnet. Mitosen sind an zwei Stellen zu sehen, an denen je zwei Mitosen nahe beisammen liegen, an andern, nicht gezeichneten Stellen des Präparates finden sie sich auch einzeln oder in größerer Zahl gehäuft.

Fig. 8 zeigt z. B. drei Mitosen aus dem Knochenmark, welche nahe beisammen liegen, eine große Zelle mit feingekörntem Protoplasma, eine kleinere hellere Zelle und eine sehr große gekörnte Zelle, welche deutlich den Charakter der eosinophilen Körnchenzelle trägt, bei stärkerer Vergrößerung.

Auch die beiden gezeichneten Präparate vom Knochenmarke entstammen verschiedenen Versuchszeiten, Fig. 7 der 7 . und Fig. 8 der 18. Stunde des Versuchs.

Die Dauer des Aufenthalts im Thermostat für die Stiickchen, nach denen gezeichnet wurde, schwankt demnach zwischen 2 und 24 Stunden. Sie beträgt für Fig. 22 Stunden, für Fig. 15 Stunden, für Fig. 3, 7, 9 und 107 Stunden, für Fig. 818 Stunden und fur Fig. 4 and 524 Stunden.

Für die Beurteilung meiner Befunde wie für spätere Weiterarbeit ist es von Interesse, daß es mir gelang, in den von mir untersuchten Geweben verschiedene Arten von Mitosen zu unterscheiden. Dieselben dürften den versehiedenen in diesen Geweben in der Norm vorkommenden verschiedenen Arten von Mitosen (und diese sind gerade in Knochenmark and Milz nicht wenige) entsprechen, wenn auch die Häufigkeit des Vorkommens im Experimente gegentuber den im Leben vorkommenden Zahlen geändert sein mag. Über das Mengenverhältnis genauere auf eingehende Zählungen bernhende Erhebungen zu machen, gestattete mein Material und meine Zeit bisher noch nicht. In der Milz konnte ich größere heller gefärbte und kleinere dunklere Zellen in Mitose sehen. Zum großen Teil scheinen mir die größeren helleren Zellen jenen auffallenden großen Zellen der Milz anzugehören, welche bei der Katze die Pulparäume auskleiden. Diese Zellen besitzen nicht nur einen großen Kern, sondern auch einen großen sich leicht mit Hämatoxylin und weniger intensiv als die roten Blutkörperchen mit Eosin tingierenden Zellleib. Sie unterscheiden sich wesentlich (namentlich durch ihre Höhe) von den Endothelien, welche wir sonst als Auskleidung von Bluträumen, insbesondere von Blatgefäßen, zu finden pflegen und ähneln in mancher Hinsicht jenen 
von A. A. Böнм ${ }^{1}$, in der Milz des Menschen zuerst beschriebenen, später auch von andern gesehenen eigentiumlichen Zellen, deren Vorkommen ich an meinen Präparaten vom Hingerichteten bestätigen kann. Die kleineren dunkleren Mitosen dagegen gehören wohl zum großen Teil andern, vielleicht gar nicht seßhaften, sondern wandernden Zellen an.

Im Knochenmark war die Zahl der leicht zu unterscheidenden Mitosen noch größer, wie ein Blick auf Fig. 8 zeigt, in welcher drei Mitosen ganz verschiedener Art gezeichnet sind, die nebeneinanderliegend gefunden wurden.

Es wurden alle Stadien der Mitose beobachtet, von den einleitenden bis zu der auf die Kernteilung folgenden Zellteilung, vgl, z. B. die verschiedenen in Fig. 3 und 5 dargestellten Formen.

Es ist mir gelungen, den sich durch das Auftreten zahlreicherer Mitosen doknmentierenden Beginn des Wachstums schon in frtherer Zeit zu beobachten, als dies CARREL beobachtete. Während nach Carrel die Latenzperiode einiger Gewebe 20 Stunden dauert, andrer reifer normaler Gewebe 24 Stunden bis 3-4 Tage, konnte ich das Auftreten zahlreicherer Mitosen bereits nach 5-7 Stunden (also schon am Abend des Operationstages) bemerken. Dies braucht jedoch keinen Widerspruch in unsern Befunden zu bedeuten, da sich Carrels Angaben wohl in erster Linie auf das Sichtbarwerden des Wachstums am ganzen Stuicke beziehen, also auf Erscheinungen, denen das Auftreten von Mitosen naturgemäß schon einige Zeit vorangehen wird.

Das erste Auftreten neuer Mitosen an der Peripherie des Stuckes beobachtete ich bereits etwa 2 Stunden nach dem Einlegen in den Wärmeofen. Freilich waren um diese Zeit die Mitosen, soweit die noch nicht gerade zahlreichen Zählungen dies erkennen ließen, nicht zablreicher als im frischen Kontrollstlick, so daß nicht mit absoluter Sicherheit bewiesen erscheint, daß diese Mitosen tatsächlich nen aufgetreten sind. Jedenfalls scheint mir der Nachweis dieser Mitosen dafür zu sprechen, daß wenigstens in dem Vorhandensein von Mitosen eine eigentliche Pause vor dem Ansteigen der Zahl derselben nicht zu bestehen braucht. In Organen und Geweben, welche im Körper in der Regel Mitosen aufweisen, dürften letztere meiner Meinung nach anch im therlebenden Gewebe von Anfang an nicht fehlen. Eine Latenzperiode in diesem Sinne scheint mir nicht vorhanden zu sein.

1) Вöнм, A. A., Über die capillären Venen Biluroths der Milz. Festschr. f. v. Kupffer. Jena 1899. Mit 5 Textfig. 
Ich möchte daher annehmen, daß die von CARREL beschriebene Latenzperiode wohl mehr auf das äußere Sichtbarwerden von Wachstumsvorgängen sich bezieht.

In Epithelgeweben erfolgt, wie dies L. LoEB ${ }^{1}$ ) vom Organismus beschrieb, die Deckung des Defekts auch im Explantat, wie ich fand; durch aktive Wanderung der Epithelzellen und die Vermehrung der Mitosen tritt erst später anf.

An Epithelzellen vermißte auch ich in meinen Präparaten das Auftreten zahlreicherer Mitosen. Doch sah ich Verschiebungen der Zellen, z. B. in der Peripherie der Schilddrüse beim Hunde, auftreten, welche mir auf ein Bestreben der Zellen hinzuweisen scheinen, den Defekt zu überkleiden.

Ich habe daraufhin meine Aufmerksamkeit anf die Regeneration der Deckepithelien in der Trachea gelenkt und konnte wiederholt Bilder seben, welche mit den von andern Forschern ${ }^{2}$ ) bei Reparation und Regeneration im Organismus beobachteten übereinstimmen. So sah ich in der Trachea der Katze, nach 7 stündigem Aufenthalt im Thermostat bei $37^{\circ}$ im Blutplasma desselben Tieres, sebr schöne Bilder von sich auf den Defekt vorschiebenden Zellen. In Präparaten, welche Mitosen sehr spärlich zeigten, sah ich die bei der Entnahme aus dem Organismus vom Epithel entblößten Teile der Schleimbaut von (im Schnitt) langgestreckten niedrigen Zellen bedeckt, wovon ich in Fig. 9 eine Abbildung gebe. Gegen die erhaltene Epithelschicht zu ließen diese Zellen den Übergang in die Basalzellen des wohlerhaltenen Flimmerepithels erkennen. An einem Präparat, welches nur 4 Stunden im Wärmeofen gewesen war, sah ich nur den ersten Anfang dieser Regeneration, während noch große Flächen des Epithels ermangelten. Vielfach beobachtete ich, daß sich abgelöste Epithelzellen, welche dann in der Nähe der Stücke im Plasma schwammen, in ihrer Form und ihrem sonstigen Verhalten änderten. So sah ich abgestoßene Becherzellen groß und rundlich werden, den Schleiminhalt, welcher sich mit Hämatoxylin blau färbte, hatten dieselben schon nach 7 Stunden vollständig abgegeben, wobei die Zellen kuglig blieben, eher größer wurden und sich mit Eosin hellrot tingierten. Der-

1) Leo LoEb, Über Regeneration des Epithels. Arch. f. Entw.-Mech. Bd. 6. 1898. S. $296 \mathrm{ff}$.

2) Bonst, M., Das pathologische Wachstum nsw. In L. Aschoff, Pathologische Anatomie. Bd. I. Jena 1909. S. $446 \mathrm{ff}$, und Marchand, Der Prozeß der Wundheilung mit Einschluß der Transplantation. Deutsche Chirurgie Lieferung 16. Stuttgart, bei F. Enke, 1901. 
artige Zellen sind in Fig. 9 über dem sich vorschiebenden Epithel im Plasma abgebildet. $\mathrm{Ob}$ anch Flimmerzellen derartige Veränderungen eingehen und etwa den Flimmersaum abstoßen, konnte ich nicht erkennen, bei den Becherzellen sah ich das Kugligwerden ganz deutlich. Die einzelnen Zellen der vorgeschobenen Deckepithelien ließen sich nicht immer deutlich voneinander abgrenzen, siehe Fig. 10. Auch L. LOEB (loc. cit.) konnte bei Epithelregeneration im Organismus eine Zellgrenze zwischen den wandernden Zellen nicht sehen. Nach 24 Stunden fand ich den ProzeB weiter fortgeschritten und ich habe bereits in meiner kurzgefaßten Mitteilung im Anatomischen Anzeiger eine Abbildung von diesem Verhalten gegeben. Das niedere Epithel hatte alle freien Schleimhautfächen überzogen, und schien bereits an manchen Stellen etwas höher geworden zu sein. Da ich lediglich über die fertigen Schnittpräparate verfugte, konnte ich nicht mit Sicherheit entscheiden, wieweit sich diese eigentümlichen Zellen tatsächlich von den Rändern des Defektes her über das Bindegewebe fortgeschoben haben, wie weit etwa an Ort und Stelle verbliebene Basalzellen unter Formänderung in sie übergehen und ob, wie neuere Forscher ${ }^{1}$ ) wieder annehmen wollen, auch amitotische Kernteilungen zur Entstehung dieses zuerst niedrig kubischen oder platten Epithels führen. Nach dem Aussehen meiner Schnitte möchte ich aber mit Sicherheit annehmen, daß es sich in meinen Befunden im überlebenden Gewebe im wesentlichen um dieselben Vorgänge handelt, welche von den Autoren als Anfangsstadien der Reparation und Regeneration im Organismus beschrieben werden.

Was beweisen nun die wiedergegebenen Abbildungen?

Wir werden uns zunächst fragen müssen, ob das Vorkommen von Mitosen in Gewebsstückchen, welche 5, 6, 7, 18, 24, 48 Stunden im Thermostat bei Körpertemperatur gehalten wurden, beweisen kann, daß diese Mitosen in diesen Stückchen erst entstanden sind, nachdem sie dem Körper entnommen worden waren, oder ob sie schon vorher darin waren. Der nächstliegende Gedanke ist ja, daß diese Mitosen noch im Körper entstanden, im Thermostat längere Zeit, ohne sich zu verändern, erhalten blieben. Hat man doch Beispiele, daß Mitosen in, dem Körper entnommenen, Gewebsstlickchen (oder nach dem Tode) noch nach 24 , ja 48 Stunden nachgewiesen werden können.

1) Borst, Das pathologische Wachstum usw. In L. Aschorf, Pathologische Anatomie. Bd. I. Jena 1909. S. 446 ff. Vgl. auch L. LoEB (loc. cit.). 
In letzterem Falle ist es ja freilich gar nicht so sicher ausgeschlossen, wie man gewöhnlich annimmt, daß auch bei gewöhnlicher Temperatur noch neue Mitosen anftreten können, wenn dies auch keineswegs gewiB ist. Dann ist aber zu bedenken, $\mathrm{daB}$ im Wärmeofen Gewebe sich in der Regel viel rascher verändern, als bei Zimmertemperatur oder auf Eis.

Um hier etwas klarer zu sehen, als man es bisher vermochte, habe ich Kontrollstiickchen nicht in Blutplasma, sondern einfach so wie sie waren, in Glasschalen (einige auch in feuchter Kammer) in den Wärmeofen bei $37^{\circ} \mathrm{C}$. eingelegt und nach 24 Stunden konserviert und geschnitten. Anch untersuchte ich Kontrollstickchen, welche bei Zimmertemperatur, und andre, welche anf Eis 24 Stunden gelegen hatten.

Dabei zeigten sich die im Wärmeofen gehaltenen Stïcke auf das hochgradigste verändert, man konnte kaum an einer Stelle noch Zellen voneinander abgrenzen, Kernkonturen waren an vielen Stellen überhaupt nicht mehr zu erkennen. Die Struktur des Stiuckes war in dem Maße ansgewischt, daß sich dasselbe kaum mehr als tierisches Gewebe erkennen ließ, sondern mehr das Ausseben einer zusammengeflossenen strukturlosen Masse, kurz die Anzeichen hochgradigen Zerfalls zeigte.

Bei Zimmertemperatur und auf Eis gehaltene Stückchen waren besser erhalten, lieBen die Struktur des Organs wohl erkennen, zeigten deutliche Zell- und Kernstruktur, wenn auch die Kerne etwas geschrumpft erschienen und nicht ganz den lebensfrischen Eindrack machten, wie die im Blntplasma im Thermostat aufbewahrten Gewebsstïckchen. Doch sah ich in Stïckchen, welche 24 Stunden auf Eis gehalten worden waren, Mitosen zahlreich und ziemlich gut erhalten, wie das in Fig. 6 dargestellt ist.

Daraus geht also hervor, daß eine 24 Stunden dauernde Einwirkung einer Temperatur von $37^{\circ} \mathrm{C}$. auf Gewebsstuickchen ohne besondere Kautelen eine direkt deletäre ist.

Es scheint demnach ausgeschlossen, daB wir in solchen längere Zeit im Wärmeofen gehaltenen Stiuckchen in der Regel noch aus dem Organismus stammende Mitosen auffinden können. Dies beweist natürlich noch nicht obne weiteres, daß die Mitosen in den Stuckchen, welche im Blatplasma (also unter besonderen Bedingungen) aufbewahrt wurden, erst außerhalb des Körpers entstanden sein mußBten. Es spricht aber dafür, daß solche Stückchen sich unter viel günstigeren Lebensbedingungen befanden, als Stückchen, welche nicht 
im Blutplasma anfbewahrt wurden. Und solche guinstige Lebensbedingungen können ein Auftreten von Mitosen begtinstigen, vielleicht sogar veranlassen, wie dies im zweiten Teil dieser Arbeit genaner begründet werden wird.

Gegen die Annahme, daß die von mir in den Blutplasmapräparaten gefundenen Mitosen bereits beim lebenden Tier vorhanden gewesen wären und sich im Thermostat unverändert über 24 , ja 48 Stunden und länger erhalten hätten, spricht ferner der Umstand, daß ich Mitosen in einigen Präparaten zahlreicher fand, als in den frisch entnommenen Kontrollstiickchen.

Wollen wir aber annehmen, daß meine Beobachtungen noch nicht zahlreich genug waren, um hierin beweisend zu sein, so entsteht die Frage, wie man es sich eigentlich vorstellen will, daB die Mitosen, wie überhanpt Gewebe, im Wärmeofen unverändert bleiben, während sie ohne Plasma darin rasch zugrunde gehen. Mitosen können wir freilich wohl erhalten, wenn wir sie konservieren, indem wir die Gewebsstickchen oder Zellen in die gebräuchlichen Konservierungsflissigkeiten einlegen. Letztere aber erhalten die Gewebe und Zellen nicht lebend, sondern töten sie ab. Das Blutplasma aber tötet die Zellen zunächst nicht $a b$, wie ich beweisen kann. Ich sah nämlich an Gewebsstückchen (Milz) rom Kaninchen in Kaninchenblutplasma nach über 6 stündigem Aufenthalt im Thermostat bei $37^{\circ} \mathrm{C}$. unter dem Mikroskop bei derselben Temperatur die lebhaftesten Bewegungen der farblosen Blutkörperchen. Es tötet also das Blatplasma die Zellen zunächst nicht $\mathbf{a b}$, es hält sie vielmehr weit länger am Leben, als Blut selbst. So sah M. Schultze ${ }^{1}$ ) im Blute schon nach 3 Stunden amöboide Bewegungen rasch aufhören, immer die konstant bleibende Temperatur von $37^{\circ}$ vorausgesetzt.

Man kann also keinesfalls annehmen, daß das Blutplasma aus dem Grande Mitosen unverändert erhalten könne, weil es die Zellen abtöte. Im Gegenteil, im Blutplasma bleiben im Thermostat die Zellen länger lebend (was die amöboide Bewegung beweist), als im Blute selbst und wohl auch ebenso lange oder länger als in der Mehrzahl der als sog. "Zusatzflussigkeiten o oder sindifferente Lösungen * bekannten Flïssigkeiten.

Da nun das Blutplasma den Zellen so ausgezeichnete Lebensbedingungen gewährt, wie dies aus meinen Versuchen hervorgeht, so

1) M. SchuLTze, Ein heizbarer Objekttisch and seine Verwendung bei Untersuchungen des Blutes. Arch. f. mikr. Anat. Bd. I. 1865. S. 22 f. Mit 2 Taf. 
ist nicht einzusehen, warum Zellen, die in das Blutplasma (bei $37^{\circ} \mathrm{C}$.) verbracht, bestimmte sich abspielende Lebensäußerungen, wie die der Mitose, plötzlich abbrechen und in irgendeiner gerade zufällig bestehenden Phase der Mitose weiterleben sollten über Stunden und Tage. Ein solches Stillestehenbleiben einer Lebenstätigkeit unter günstigen Lebensbedingungen wäre zum mindesten ebenso schwer zu beweisen, wie die gegenteilige Annahme, und dabei weniger wahrscheinlich, weil andre Lebensäußerungen sichtlich fortdauern.

Ich glaube im vorausgehenden verschiedene gute Gründe dafür beigebracht zu haben, daß die von mir in den überlebenden Geweben beschriebenen Kernteilungen nicht vom Organismus her vorhandene sind, sondern sich im tiberlebenden Stücke gebildet haben. CARREL hat ja auch noch andre Beweismittel angefuhrt, so z. B. durch direkte Zählungen der Zellen, bei welchen sich ergab, daß die Zellen im überlebenden Stiick im Wärmeofen tatsächlich an Zahl zugenommen haben.

Der letzte Beweis für die Richtigkeit dieser Annahme wird übrigens auch dann noch nicht erbracht sein, wenn es gelingt, die Vermehrung der Zellen direkt, etwa an einem in den Wärmeofen eingebauten Miskroskop, zu beobachten. Denn in diesem Falle kann ja wieder eingewandt werden, daß die direkt gesehenen Zellvermehrungen nur mit amitotischen Kernteilungen einhergehen, wie sie ja neuerdings von seiten mancher Pathologen ${ }^{1}$ ) wieder als ein zur Entstehung von Geweben fuhrendes Gestaltungsgeschehen angenommen werden. Die Mitose selbst aber hier mit Sicherheit zu erkennen, durfte nicht ganz leicht sein.

Auch Burrows (loc. cit.) hat bei embryonalem Gewebe die tatsächliche Zellteilung niemals vollständig unter dem Mikroskop verfolgen können, während in dem gefärbten Objekte alle Stadien der Mitose leicht gefunden wurden bei Präparaten unter 6 Tage Alter.

Besondere Schwierigkeiten für diesen doch nicht ganz unmöglichen und bei der Höhe, auf welcher die vitalen Färbemethoden heute stehen ${ }^{2}$ ), in nicht allzuferner Zukunft zu erwartenden Nachweis er-

1) Borst, Das pathologische Wachstum usw. In L. Aschoff, Pathologische Anatomie. Bd. I. Jena 1909. S. $446 \mathrm{ff}$.

2) Fischel, Alfred, Über die Untersuchungen iber vitale Fïrbung an Süßwassertieren, insbesondere an Cladoceren. Leipzig 1908. 69 S. 2 Taf. GoldmanN, E., Die äßere und innere Secretion des gesunden Organismus im Lichte der vitalen Färbung. Beitr. zur klin. Chir. Bd. 64. S. 192-26j̃. 1909. Mit 15 Taf. - und andre Autoren. 
wächst auch aus dem von mir gefundenen oben beschriebenen Umstande, daß die Mehrzahl der Mitosen nicht ganz peripher am Stlicke ablänft, sondern in einiger Entferung von der äußeren Oberfläche, was die direkte Beobachtung erschwert.

Für die Beweisführung zugunsten des tatsächlichen Vorkommens von Vermehrungserscheinungen im uiberlebenden Gewebsstuck möchte ich noch eine von mir gemachte auch in andrer Hinsicht wichtige Beobachtung über die Lage der Mitosen im uiberlebenden Stuick anfügen. Es zeigte sich, daß die Mitosen in den eingelegten Sticken nicht so gleichmäßig wie in frischen Kontrollstücken verbreitet waren, sondern sich an der Peripherie des Stlickes mehr häuften. Dabei war die ganze Peripherie nicht gleichmäBig beteiligt, sondern an manchen Stellen, welche öfters Prominenzen am Rande des Stlickes bildeten, erschienen Anhäufungen von Mitosen, während sie an andern Stellen ganz fehlten. An den Stellen des Vorkommens von Mitosen lagen dieselben, wie einige Male beobachtet wurde, entweder ganz peripher, so daB sie als letzte Zellen in das Blutplasma eintauchten (s. Fig. 4). An andern Stellen, und das war das häufigere, lagen Gruppen von Mitosen in einiger Entfernung (etwa 5-10 Zellbreiten) von der Oberfläche des Stückes entfernt (s. Fig. 1), so daß die aus dem Stücke hervorwachsenden Zellen offenbar nicht die zuletzt entstandenen waren. Man könnte auch hier vielleicht von einer Matrix reden, welche das vordringende Zellmaterial von geschtitzterer Stelle aus liefert.

Eine derartige Anordnung der Mitosen, welche besonders in der Milz deutlich war, habe ich in den frisch eingelegten Kontrollstiickchen niemals gesehen. Daß dieses auffällige Verhalten etwa dadurch bedingt wäre, daß die Mitosen aus dem Innern des Stïckes nicht durch Wachstum, sondern durch Innendruck herausgepreBt wären, kann ich nicht annehmen, da dann die gruppenweise Anordnung der Mitosen unverständlich bliebe.

Zum Verständnis dieses Verhaltens kann wohl folgender Umstand beitragen. Ich sah wiederholt, wenn ich größere Gewebestückchen in Blutplasma einlegte, daß nur die Peripherie des Stückes gut erhalten blieb, während im Innern des Stückes Kerne und Zellen Veränderungen zeigten. So fand ich z. B. bei der Schilddrüse des Hundes in Hundeblutplasma nach 24 Stunden die periphere wohlerhaltene Zone etwa $0,2 \mathrm{~mm}$ breit. Wenn also an der Peripherie die Lebensbedingungen günstigere sind, so werden dort wohl auch am ehesten Mitosen zu erwarten sein. 
Die im Blutplasma uberlebenden Stückchen, also die Explantate, verhalten sich in diesem Punkte ubereinstimmend mit Transplantaten, von denen z. B. Borst ${ }^{1}$ ) sagt: ,Umfangreiche Transplantate werden nar in der Peripherie genügend ernährt, die centralen Teile sterben ab.

Auch für künftige Experimente dürfte diese Angabe von Wert sein, da sie zeigt, daß die ins Blntplasma einzulegenden Stlickchen nicht mehr als $0,4 \mathrm{~mm}(2 \times 0,2)$ in der Dicke betragen dürfen, weil sonst die im Innern liegenden Teile nicht gentigend ernährt werden. Es gilt diese Zahl natïrlich nur für diesen speziellen Fall und wird in andern Fällen (z. B. für andre Gewebe) entsprechend zu modifizieren sein. Noch ist beizufügen, daß die Stuickchen besser wachsen, wenn sie nicht am Boden der Glasschale ankleben. Es empfiehlt sich daher weniger, die Stückchen erst in die Glasschalen zu legen und dann Plasma zuzugeben, sondern mehr, Plasma erst in die Schalen zu verbringen und dann die Stückchen zuzugeben, damit dieselben allseitig vom Blntplasma umspült sind. Für Präparate auf Objektträgern und Deckgläschen, zumal wenn man nur die Peripherie des Stückchens in der Gesichtsfeldebene untersuchen will, wird man mit Vorteil erst das Präparat auflegen und dann das Plasma zugeben, wie es CARREL vorgeschrieben hat.

Freilich sah ich in andern Präparaten wieder ganz andre Bilder, welche ich nicht als Wachstnmserscheinungen denten kann. So z. B. zeigten wiederholt in der Leber von der Katze und andrer Tiere, gerade in der peripheren Zone des Präparates, die Leberzellkerne eigentümliche Anordnung des Chromatins in Püktchen, welche ich als caryolytische bzw. autolytische Figuren auffassen möchte. In der Niere fand ich öfters die Zellen vor den Kernen degeneriert. Ohne Zweifel wird bei allen diesen ubberaus wechselnden Verhältnissen die jeweilige Beschaffenheit des Mediums, also des Blutplasmas und noch manches andre des technischen Verfahrens, was uns heute noch unbekannt ist, eine wichtige Rolle spielen.

Jedenfalls dürfen wir aber annehmen, daß das Wachstum, soweit ein solches erwiesen erscheint, wenigstens zu Anfang weniger dadurch erfolgt, daß die am meisten exponiert liegenden Zellen an Zabl zunehmen, vielmehr dadurch, daß die zwar nahe aber nicht unmittelbar ganz an der Peripherie liegenden Zellen sich vermehren.

1) Borst, Das pathologische Wachstum usw. In Aschoff, Pathologische Anatomie. Bd. I. 1909. S. 480. 
Es besteht ferner die Frage, ob die Annahme längeren Fortbestehens des Lebens in den sog. * überlebenden Stücken * überhanpt gerechtfertigt ist. Wir haben gesehen, daß friihzeitig im Plasma Gerinnung eintritt, welche auch CARREL nicht aufzuhalten vermochte. Er sagt vom Plasma, welches er anf die Präparate brachte: „Es gerinnt fast unmittelbar daranf. $*$ Auch mir gelang es nicht, trotz mannigfacher Versuche, die Gerinnung längere Zeit hintanzuhalten, ohne zu Mitteln zu greifen, welche dann wieder die Präparate schädigen.

Obwohl wir, wie MARCHAND ${ }^{1}$ ) ausführt, einer Flüssigkeit im allgemeinen Lebenserscheinungen nicht zusprechen können, dürfen wir doch von »lebendem Blute * reden in dem Sinne, daß wir dabei nicht bloß die zelligen Elemente, sondern die Gesamtheit von Zellen und Intercellularsubstanz im Sinne haben.

Auch StudničKa ${ }^{2}$ ) ist der Ansicht, daß wir einige seiner $>$ Rheoplasmen*, zu denen er auch das Blutplasma rechnet, kaum für ein totes Secret halten dürfen.

Es ist aber fraglich, ob wir ein geronnenes Plasma (auch nach Braus [1. c.] sind die Fibrinfäden tot) noch als lebend betrachten dürfen. Ist es aber tot, wer bürgt uns dafür, daß die darin eingeschlossenen Zellen am Leben bleiben, daß die Gerinnung nicht auch anf sie fortschreitet, bei manchen Zellen früher, bei andern Zellen später.

Weiter sagt MaRchand an derselben Stelle: Anderseits wissen wir, daß wirklich leblose, abgestorbene und absterbende Teile noch längere Zeit in dauernder Verbindung mit dem lebenden Gewebe bleiben, wie die Hornschicht der Epidermis. Dies Beispiel zeigt deutlich, daß der Übergang zwischen lebenden und leblosen Elementen anch im normalen Organismus ein ganz allmählicher sein kann, daß also graduelle Abstufungen der Lebenseigenschaften in den einzelnen Teilen stattfinden.*

Dann haben wir auch den Vergleich mit Bakterien usw., welche auf unzweifelhaft toten Nährboden wohl gedeihen. Bakterien sind aber ganze Organismen, Explantate dagegen nur Teilsticke soleher. Immerhin ist zum mindesten der mit so vieler Mühe hergestellte $\mathrm{Zu}$ sammenhang mit dem lebenden Plasma des Blutes in unsern Versuchen tatsächlich nicht erreicht. Es sind damit bisher bei der Ex-

1) Marchand, Einleitung zu Krehl und Marchand8 Handbuch der allg. Pathologie. Bd. I. 1908. S. 7.

2) StudničKA, F. K., Ǔber $\gg$ Bausubstanzen körpers überhaupt. Anat. Anz. Bd. 39. Nr. 9 n. 10. 1911. S. 225-237. 
plantation die günstigen Verhältnisse nicht geschaffen, wie wir sie z. B. bei manchen Transplantationen herbeifuhren können, bei denen wir die Transplantate dauernd immer wieder aufs nene mit dem herantretenden unveränderten Blutplasma des Körpers, sei es unter Vermittlung der Lymphe oder direkt in Verbindung bringen können. Anderseits findet sich aber anch viel Übereinstimmendes mit den Transplantationen oder einfachen Wundheilungen, wie wir sie besonders durch Marchand ${ }^{1}$ ) kennen gelernt haben, indem auch bei Explantaten wie bei Wundheilungen eine vorläufige Bedeckung der Wundflächen durch Fibrin erfolgt, worauf dann die eigentlich regenerativen Veränderungen erfolgen.

Das Fibrin kann vielleicht in unserm Falle in gewisser Hinsicht als "Bauplasma im Sinne von Studnıčka (loc. cit.) dienen.

Diese Erwägang über die Bedeutung meiner Experimente haben mich zu dem Ergebnis gefuhrt, daß die Aufgabe des Plasmas bei den Kulturversuchen mit überlebenden Geweben gar nicht sein wird, alles das, was der Organismus vom ungeronnenen (lebenden) Plasma erhält, in derselben Form darzubieten. Es kann ja auch, und das scheint mir sehr wesentlich, der Vorteil des Einlegens in Plasma gerade darin liegen, daß dasselbe sofort gerinnt und damit der Wundfläche zunächst das ersetzt, was dieselbe durch ihr Ausscheiden aus dem Verband des Organismus verloren hat.

Dieser Verlust aber besteht meines Erachtens vor allem darin, daß die Zellen aufhören, mit den benachbarten Zellen in Verbindung zu stehen. Die Verbindung mit Nachbarzellen kommt allen Zellen des Metazoenkörpers (für die freischwimmenden Zellen unter Vermittlung des Blutplasmas oder der Gewebssäfte) za. Dabei bleibt es gleichgültig, ob diese Verbindung (um nur einige Beispiele herauszugreifen), eine allseitige ist (eventuell unter Vermittlung einer Intercellularsubstanz), wie bei den Zellen der Bindegewebsgruppe, oder ob sie infolge einer mit der polaren Differenzierung verbundenen Entwicklung einer freien Oberfläche und einer Basis, wie dies bei den Epithelien geschieht, sich auf die sog. „Seitenflächen «2) reduziert.

Bei solchen zuvor mit den Nachbarzellen in Verbindung stehenden Zellen vermag, wenn sie isoliert werden, das aus dem Plasma

1) Marchand, Der Prozeß der Wundheilung mit Einschluß der Transplantation. Deutsche Chirurgie. Lieferung 16. Stuttgart, bei F. Enke, 1901.

2) OPPEL, A., Lehrbuch der vergleichenden mikroskopischen Anatomie der Wirbeltiere. Teil III. Mundhöhle, Bauchspeicheldrüse und Leber. Jena 1900. S. 491. 
sich niederschlagende Fibrin die fehlenden Nachbarzellen zunächst zu ersetzen, solange bis die Zellen sich den veränderten Verhältnissen angepaßt haben. Die Anpassung an die veränderten Verhältnisse würde darin bestehen, daß die Zellen entweder eine gegen das Medium gerichtete $»$ freie Oberfläche* bilden, wie dies bei den Epithelien der Fall ist, oder daß sie allseitigen Anschluß an andre Zellen oder Intercellularsubstanzen gefunden haben, wie sie ihn bedürfen. Vermögen die freigelegten Zellen nicht, sich in einer der angedeuteten Richtungen anzupassen, so werden sie frïher oder später zugrunde gehen.

Versuche der Zellen, sich den geänderten Lebensbedingungen anzupassen, möchte ich daher in manchen der Vorgänge erkennen, welche wir an den überlebenden Gewebsstückchen sich abspielen sehen. Hierher würde nicht nur das Verhalten der Deckepithelien gehören, welche sofort eine neue sfreie Oberfläche herausarbeiten, sondern auch die rasche Vermehrung andrer Elemente. Diese Vermehrung der Zellen würde einen Versuch der Zellen darstellen, mit Nachbarzellen in Verbindung zu treten, indem sie den klaffenden Raum durch Wachstum überbrücken. Dieser Versuch verläuft allerdings in unserm Experiment zum Teil resultatlos, da die Zellen in den Glasschalen radiär in den unbegrenzten Raum auswachsen. Wird der Versuch aber in die richtigen Bahnen geleitet, so kann er von praktischem Werte werden, und er ist auch bereits, wie es das Beispiel der einfachen $W$ undheilung zeigt, im täglichen Leben aufs segensreichste für die Menschheit zur Wirkang gelangt, und dies wiederbolt sich täglich.

Ich komme somit in diesem experimentellen Teil zum Resultat, daß die von mir in überlebenden, im Thermostat bei $37^{\circ} \mathrm{C}$. im Blutplasma aurbewahrten Gewebsstiickchen von Sängetieren längere Zeit, nicht nur Stunden, sondern Tage lang am Leben erhalten werden können. Als beweisend für meine Annahme halte ich die von mir und andern Autoren beobachteten und bestätigten Lebenserscheinungen, welche sich an solchen Gewebsstückchen wahrnehmen lassen. Hier gehören neben der Selbstbewegung die mit Reparation und Regeneration einhergehenden Vorgänge verschiedener Art. Von diesen konnte ich besonders auf die bei Reparation ron Epitheldefekten auf Schleimhäuten sich vollziehenden Epithelverschiebungen aufmerksam machen, in denen ich außerhalb des Körpers experimentell erzeugbare Lebenserscheinungen fand.

Den endgiultigen Nachweis dafur zu erbringen, daß auch die be- 
obachteten Mitosen tatsächlich erst im überlebenden Gewebe entstanden sind, halte ich für äußerst wichtig und weiterer Arbeit wert. Ich gebe daher am Schlusse der Arbeit in der Zusammenfassung der Resultate noch eine Übersicht uiber diejenigen Punkte, welche mir für eine Bejahung dieser Frage zu sprechen scheinen.

Sollten aber auch nicht alle heute von CaRreL vertretenen Lehren ernsthafter Prüfung standhalten, so glaube ich doch, daß die von ihm ausgearbeitete Methode der Kultur überlebender Gewebe noch manchen Nutzen für die biologische und causale Forschung bringen wird.

Jedenfalls halte ich es durch die bei meinen Experimenten gemachten Beobachtungen für erwiesen, und ich kann damit die Annahmen früherer Autoren bestätigen, daß das Blntplasma von Sängetieren ein Medium darstellt, in welchem Gewebsstickchen bei Körpertemperatur lange Zeit hindurch Lebenstätigkeiten ausführen, also am Leben zu bleiben vermögen. Wenn auch Quantität wie Qualität dieser Lebenstätigkeiten noch weiterer Erforschung bedarf, so stellt doch das Vorhandensein derselben eine soweit gesicherte Tatsache unsres Wissens dar, daß es berechtigt und notwendig erscheint, dieselben der causalen Analyse zu unterwerfen und zur Grundlage causaler Folgerungen zu machen. Der causalen Analyse möchte ich daher diejenigen causalen Schltisse anreihen, welche mir aus meinen Experimenten zunächst sich zu ergeben scheinen.

\section{Causale Folgerungen.}

Es wurde bereits von verschiedenen Seiten [so durch Marchand 1), SaLtykow 2) und andre Autoren] darauf hingewiesen, daB Teile höherer Organismen, selbst der Säugetiere und des Menschen, nachdem sie vom Organismus abgetrennt worden sind, nicht sofort absterben. Unter günstigen Umständen können solche abgetrennte Teilstlicke, wenn sie demselben oder einem andern Organismus wieder eingepflanzt werden, weiter leben und einheilen. Man spricht dann von einer Implantation (funktionellen Transplantation) im Sinne von Roux ${ }^{3}$ ), für welche nach diesem die notwendigen Bedingungen sind:

1) Marchand, F., Der Prozeß der Wundheilung mit Einschluß der Transplantation. Deutsche Chirurgie. Stattgart 1907.

2) Saltykow, S., Über Transplantation zusammengesetzter Teile. Arch. f. Entw.-Mech. Bd. 9. 1900. S. $329 \mathrm{ff}$.

3) Roux, W., Gesammelte Abhandlungen uber Entwicklungsmechanik der Organismen. Bd. 1. Leipzig 1895. S.404, Anm. 
Vollkommen geeignete Ernährung und genügend rascher funktioneller Reizanschluß, sowie nach OPPEL ${ }^{1}$ ) im Speziellen noch die zu ersterer erforderliche *biochemische Übereinstimmnng*. Auch wenn das überpflanzte Stück nicht dauernd (d. h. nicht so lange wie der Organismus, mit dem es verbunden wird) am Leben bleibt, kann es wenigstens eine Zeitlang fortleben, vielleicht so lange, bis das Transplantat einen durch die Funktion verursachten Ersatz (Substitution) des Transplantats durch körpereigenes Gewebe ermöglicht hat. Doch ist es im letzteren Falle, in welchem ich ${ }^{2}$ ) vorgeschlagen habe von Interplantation zu reden, noch unentschieden, and wechselt wohl von Fall zu Fall, wie lange das interplantierte Stiuck lebt, da ja selbst lebloses Material solchen Zwecken dienlich gemacht werden kann.

Den jünsten Forschungszweig endlich, die Kultur uberlebenden Gewebes außerhalb des Organismus, bezeichnen wir mit einem von W. Roux gebrauchten Ausdruck als $»$ Explantation , Auspflanzung. Im Gegensatz zur einfachen Entnahme und Beobachtung von Gowebssticken, wie sie etwa zum Studium der Autolyse ohne besondere Hinzufugung gemacht wird, und wie sie anch in einigen der von mir im ersten Teil dieser Arbeit mitgeteilten Experimente (Lagern von Gewebsstücken auf Eis oder im Wärmeofen ohne Zusatz) geschah, sind unter Explantation nur solche Experimente zu verstehen, bei welchen die dem Organismus entnommenen Gewebsstückchen in ein Medium verbracht werden, welches (ohne selbst ein Organismus zu sein) das Fortleben des explantierten Gewebes ermöglicht.

Die Bedingungen für das Fortleben (Überleben) explantierter Gewebe, besonders auch für die Möglichkeit einer längeren Dauer desselben, bedturfen dringend noch weiterer Erforschung, da es sich dabei um eine überaus wichtige Lebenseigenschaft handelt, deren Konsequenzen fur die verschiedensten Wissensgebiete der Biologie, insbesondere auch fur die Medizin, namentlich die Chirurgie und damit für das praktische Leben bereits von größter Bedentung geworden sind und noch von viel höherer Bedeutung werden können. Wohl sind eine Reihe der Tätigkeitsformen, welche nach der funktionellen Definition des Lebens von W. Roux ${ }^{3}$ ) bei Lebewesen bekannt

1) OpPé, A., Über die gestaltliche Anpassung der Blutgefäße usw. Vortr. u. Aufs. üb. Entwicklungsmech. d. Organismen, herausgeg. v. W. Roux. Hft. 10. 1910. S. 151 ff. a. 160 f.

2) OPPEL, 1. c. S. 150 .

3) Roux, W., Vorträge und Aufsätze über Entwicklungsmechanik der Organismen. Hft. 1. 1905. S. 105, und Die angebliche künstliche Erzeugung von Lebewesen. Wochenschr. Die Umschau. Nr. 8. 1906. 
und für diese charakteristisch, sogar in verschiedenem Grade unentbehrlich sind, für solche dem Organismus entnommene Teilsticke bereits nachgewiesen, und es bildete in der zweiten Hälfte des verflossenen Jahrhunderts einen Triumph experimenteller Forschung, als es M. SchuLtze ${ }^{1}$ ) gelang, uns dureh Konstruktion seines heizbaren Objekttisches eine derjenigen Bedingungen (Erhaltung der Körpertemperatur) zu schaffen, welche es ermöglichen, an überlebenden, einem Säugetiere oder dem Menschen entnommenen Teilstücken, z. B. bestimmten im Blute vorkommenden farblosen Blutkörperchen, den sog. Wanderzellen, einen wichtigen Lebensvorgang, nämlich den der Selbstbewegung ${ }^{2}$ ) nicht nur direkt zu sehen, sondern auch eine Zeitlang zu erhalten und experimentell zu beeinflussen.

Schon bei diesem Versuche, der so einfach ist, daß er in der Vorlesung ansgefuhrt werden kann, zeigte es sich bald, daß für ein Erhaltenbleiben des Lebens (soweit dasselbe als Bewegungsmöglichkeit in die Erscheinung tritt) nicht allein die Temperatur ausschlaggebend ist, daß vielmehr auch andre Faktoren mitwirken.

Ein damals von M. Schultze angestelltes (1. c. S. $22 \mathrm{f}$.) in andrer Hinsicht verwertetes Experiment, scheint mir auch causale Bedeutung zu haben. Ein Tropfen frischen Menschenblutes unter Deckgläschen in der feuchten Kammer zwischen 36 and $38^{\circ} \mathrm{C}$. aufbewahrt, zeigte noch nach 3 Stunden an einigen wenigen farblosen Blutkörperchen Bewegungen, welche aber nach karzer Zeit anfhörten. Unter denselben Kautelen aber bei $3-5^{\circ} \mathrm{C}$. aufbewahrt, zeigte sich der Blutstropfen viele Stunden lebensfähig, wie die bei der Erwärmung auftretenden lebhaften kriechenden Bewegungen der farblosen Blutkörperchen bewiesen. Größere Quantitäten von Blut in Gläsern aufbewahrt bei durchschnittlich $5^{\circ} \mathrm{C}$. enthielten sogar nach Verlauf von 5 und 6 Tagen noch bewegliche farblose Blutkörperchen, wie Proben zeigten, welche auf dem heizbaren Objekttisch bis $38^{\circ} \mathrm{C}$. erwärmt wurden.

Daraus scheint mir ohne weiteres hervorzugehen, daß die Körpertemperatur nicht der einzige Faktor ist, welcher das Leben explan-

1) Schultze, M., Ein heizbarer Objekttisch und seine Verwendung bei Untersuchungen des Blutes. Arch. f. mikr. Anat. Bd. 1. 1865. S. 1-42. Mit 2 Taf. Vgl. hier die ältere Literatur.

2) Ich gebrauche das Wort $>$ Selbst< im folgenden stets in der von Roux aufgestellten causal-analytischen Bedeutung, daß die sdeterminierenden , also die besondere Art des betreffenden Geschehens bestimmenden, nicht also auch notwendigerweise die das Bestimmte srealisierenden. Faktoren in dem betreffenden Gebilde selbst gelegen sind. 
tierter Teile erhält, wiewohl sie einen Faktor darstellt, welcher bestimmte Lebenserscheinungen (z. B. Bewegung) hervorruft. Warum aber erhält sich bei niederer Temperatur, wie es die Experimente M. Schultzes zeigen, die Bewegungsmöglichkeit der Wanderzellen im Blute länger als bei Körpertemperatur? Meiner Meinung nach ist es nicht die niedere Temperatur selbst, welche die Bewegungsfähigkeit erhält (da ja letztere bei höherer Temperatur gesteigert ist), sondern der Umstand, daß bei niederer Temperatur andre das Leben der Zelle schädigende Faktoren nicht so zur Geltung kommen können, wie bei höherer Temperatur.

Es ist bekannt, daß bei höherer Temperatur Körpergewebe, besonders der Ader entnommenes Blut, sich rascher verändern, als bei niederer Temperatur. Literatur für diesen Satz anzuführen ist nicht erforderlich, da derselbe den Erfahrungen des täglichen Lebens entspricht. Auch zeigt eines meiner im ersten Teil dieser Arbeit mitgeteilten Experimente die histologischen Veränderungen, welche dabei auftreten.

Wenn somit Lebenseigenschaften (wie die Selbstbewegung) der Zellen durch die Körpertemperatar keine Schädigung erfahren, werden wir von selbst darauf geleitet, daß es andre in den Zellen und Geweben sowie in dem umgebenden Medium wirkende Faktoren sein werden, welche bei höherer Temperatur mehr zur Geltung kommen als bei niederer Temperatur. Ich glaube, daß diese Faktoren besonders im amgebenden Medium gelegen sind, weil je nach der verschiedenen Beschaffenheit dieses Mediums die Veränderungen sich verschieden rasch vollziehen.

Darin liegt eine causale Bedeutung des von mir oben mitgeteilten Experimentes, bei dem es mir gelang, Wanderzellen im Blutplasma nach 6 Stunden Aufenthalt im Wärmeofen noch in lebhafter Bewegung zu sehen, während M. Schultze im Blute selbst schon nach 3 Stunden die Bewegungen der Wanderzellen rasch aufhören sah. Bei meinem Versuche gelang es demnach durch Entfernung der Blutkörperchen aus dem Blute denjenigen Faktor auszuschalten, welcher das. Aufhören der Bewegung bewirkt hatte.

Im Blute sterben also die in ihm schwimmenden oder liegenden Zellen und Gewebe außerhalb des Organismus bei Körpertemperatur rascher ab, als im Blutplasma. Es geht daraus hervor, von welcher Wichtigkeit es ist, daß dem Organismus entnommene Zellen oder Gewebsteile sich in einem geeigneten Medium befinden. 
Die Möglichkeit, die Dauer des Lebens der untersuchten Zellen und Gewebe nach ihrer Entnahme aus dem Körper zu verlängern und die Selbstbewegung an ihnen zu untersuchen, hängt demnach neben der Erhaltung der Körpertemperatur in besonders hohem Maße von der Wahl eines geeigneten Mediums ab.

Auch auf andre Lebenstätigkeiten, wie die Selbstveränderung (Dissimilation), die Selbstausscheidung und die Selbstwiederbildung (Assimilation) haben derartige Untersuchangen schon einiges Licht geworfen, indem man sich verschiedener Medien, der sog. Zusa.tzflüssigkeiten bediente.

Die bisher angewandten Methoden gaben dagegen beim Studium andrer Lebensvorgänge noch nicht die erwünschten Resultate, so vor allem für die Erkenntnis der Selbstteilung. In dieser haben wir bestimmt koordinierte Selbstbewegungen zu sehen, welche zugleich durch die "qualitative Halbierung * Rouxs ${ }^{1}$ ) die Vererbung, eine Selbsttubertragung der Eigenschaften des Trägers, auf die Teilprodukte (Nachkommen) herbeiführen.

Die reichen, in neverer Zeit mit Transplantationen gemachten Erfahrungen scheinen zwar auf den ersten Blick nicht ungeeignet, auch die Lösung dieser Frage beim Explantat zu fördern, und mancher wird vielleicht danach annehmen, daß die Frage bereits bejahend beantwortet sei, wenn im "Transplantat* Kern- und Zellteilungen gefunden sind. Bei dieser Betrachtungsweise wlirde aber ganz die Rolle des Organismus, auf welchen transplantiert wurde, anßer acht gelassen, und dies wäre ein Fehler.

Die Bedeutung der postulierten Zellvermehrung in einem dem Organismus entnommenen, in ein Medium explantierten Teilstick (also im $\gg$ Explantat ) liegt ja eben darin, daß das Teilstück zur Zeit der Zellvermehrung mit keinem, auch nicht mit einem fremden Organismus verbunden ist. Erst solchen, in einem jedes Anschlusses an einen Organismus entbehrenden Teilstücke beobachteten Zellvermehrungen kann nicht nur jene praktische Bedeutung zukommen, von der bereits im ersten Abschnitt die Rede war, sondern diese werden auch die wichtige causale Bedeutung haben, auf welche ich im folgenden aufmerksam machen möchte. Durch die Loslösung des Teilstiickes aus dem Organismus wird die Wirkung von Faktoren im Experimente ausgeschaltet, welche bisher nicht nur für die Zellvermehrung als

1) Roux, W., Vorträge und Anfä̈tze. Hft. 1. 1905. S. 105, und Die angebliche künstliche Erzeugung von Lebewesen. Wochenschr. Die Umschau. Nr. 8. 1906. - Vgl. auch OPPes, A., in Rouxs Vortr. u. Aufs. Hft. 10. 1910. S. 61. 
solche, sondern auch für weitere mit Zellvermehrung einhergehende Vorgänge, wie Wachstum, Wundheilung, Implantation, Regeneration, von Wichtigkeit erschienen. Es kann dieser Versuch lehren, daß für manchen mit Zellvermehrung einhergehenden Vorgang, auch wenn sich derselbe im Organismus selbst vollzieht, Faktoren weniger wichtig sind oder ganz wegfallen können, welche bisher dabei doch mehr oder minder eine Rolle zu spielen schienen. Kann doch im explantierten Teilstick die Wirkung des Centralnervensystems oder anch nur ịrgendwelcher weiter herkommender Nerven, ja bei Entnahme nur einzelner Zellen jede Nervenwirkung mit Sicherheit ausgeschlossen werden. Dabei ist aber im Auge zu behalten, daß dieser Nachweis selbstverständlich das Bestehen einer Nervenwirknng bei Wachstums- oder Regenerationsvorgängen innerhalb des Organismus selbst keineswegs ausschließt. Nur wäre daran zu denken, daß die Wachstumsvorgänge sich beim Fehlen des Nervenreizes (etwa in ihrer Richtung, in ihrem Maße, in ihrem Orte und in ihrer Zeit) sich verändern werden, gegentuber dem unter dem Einfluß des Nervensystems oder andrer vom Organismus ausgehender Regulationsfaktoren erfolgenden Wachstum.

Es werden also die Wachstumsvorgänge in unsern Explantationsexperimenten am überlebenden Gewebe in reinerer Form beobachtet werden können, als im Organismus selbst, weil explantierte Gewebe nicht der Regulation von seiten des Organismus unterliegen. Diese aber ist, wie Roux markant sagt, der Feind unsrer Erkenntnis der stypischen * Wirkungen und ihrer Faktoren.

Neben der Möglichkeit, einen für die Zellvermehrang bedeutungsvollen Faktor, das Nervensystem und damit jede Regulation durch Nervenvermittlung bei solchen Versuchen auszuschalten, können wir durch geeignete Wahl und beliebige Veränderung des Mediums, in welches wir das dem Organismus entnommene Stück verbringen, weitere Faktoren heranbringen und ihr Wirken in weit reinerer Form beobachten, als dies bei einer Applikation im Organismus selbst, besonders infolge der stets das Experiment am Organismus erschwerenden sonstigen (also etwa nicht unter Vermittlung des Nervensystems sich rollziehenden) Regulation von. seiten des Organismus möglich wäre.

Für die Anordnung der Versuchsbedingungen erweitert sich damit das Gebiet in ungeahnter Weise. Chemische, mechanische, thermische, photische und elektrische Reize werden künftighin Wirkungen 
erzeugen, welche, da sie durch keinerlei Regulation von seiten des Organismus gestört werden, nunmehr in reinster Form zur Beobachtung gelangen.

Damit, daß das Vorhandensein einer Zellvermebrung sowie andrer Wachstumsvorgänge außerhalb des Organismus zum Teil wahrscheinlich gemacht, zum Teil nachgewiesen wurde, ist die Ursache, welche diesen Vorgang veranlaßt, noch keineswegs erkannt. Gewiß ist es gelungen, den Komplex der Faktoren wesentlich einfacher zu gestalten, indem eine Reihe zuvor nicht mit Sicherheit anszuscheidender Faktoren nunmehr in Wegfall kommen. Wie im vorausgehenden dargelegt wurde, kommt das Nervensystem als Faktor hier in Wegfall. Ebenso kann die Veranlassung zum Wachstum des ausgeschnittenen Gewebsstückchens nicht mehr von dem Organismus als Ganzem oder von dessen Teilen: Increten ${ }^{1}$ ), Hormonen usw. ausgehen. Soweit es sich hier um Individualität handelt, kann dieselbe also nur noch dem Teilstiuck oder den dasselbe zasammensetzenden Teilen zukommen.

Da also jeder auf den Organismus bezligliche funktionelle Reizanschluß für das ausgeschnittene Stück fehlt, da ferner eine Regu-

1) Den von mir 1906 (Ergebnisse d. Anat. u. Entwicklungsgesch. Bd. 16. S. $231 \mathrm{ff}$ ) vorgeschlagenen Terminus sIncretions (daza $\rightarrow I n c r e t s$ und sincernierens) möchte ich beibehalten anch aus dem Grunde, weil derselbe nichts über die Beschaffenheit des Increts aussagt und daher neben den Hormonen (Reizstoffen) auch andre Increte, z. B. nicht reizende Zellprodukte, Fermente usw. einbegreift und somit eine ausgedehntere physiologische und causale Verwendbarkeit besitzt. Ich habe unter die incernierenden Elemente früher nur Epithelien eingereiht, weil ich in der Incretion eine Tätigkeit sehe, welche von der diesen Elementen zukommenden Secretion grundsützlich verschieden ist, indem sie in der Richtung nach der Basis der Zelle erfolgt, während die Secretion an der sfreien Oberfläche « der Zelle geschieht, ferner weil zwischen Secretion und Incretion Wechselbeziehungen bestehen, welche auf das Vorhandensein einer gegenseitigen Abhängigkeit beider Tätigkeitsformen voneinander in causaler. correlativer, funktioneller oder sonstiger, noch nicht bekannter Hinsicht hinweist. Ich stehe aber dem von KrehL, Abderhalden, Goldmann (Beitr. zur klin. Chir. Bd. 64) und andern Autoren geänßerten Gedanken, daß bei der In. cretion des Organismus auch dem Bindegewebe eine Rolle zufällt, durchaus freundlich gegenüber. Da Fitrings Vorschlag (Zeitschr. f. Botanik. 2. Jhrg. Hft. 4. 1910. S. 225-267), den Terminus s Hormone auch für Pflanzen zu verwenden, aber darunter bloß solche Reizstoffe zu verstehen, welche die Entwicklungsvorgïnge beeinflussen, eine weitere Einschränkung der Hormone anstrebt, dürfte sich um so mehr der allgemeine Gebrauch des Terminus sIncretionc, welcher alle Increte einbegreift, empfehlen. Einige Autoren scheinen aber auch heute noch bei dem schwerfalligen Terminus sinterne Secretionc oder sinnere Secretion* beharren zu wollen. 
lation vom Organismus aus auf das ausgeschnittene Stück nicht mehr erfolgen kann, müssen bei der Explantation alle Faktoren, welche das Wachstum bedingen, in den ausgeschnittenen Zellen (oder Geweben), also im Explantate selbst liegen oder denselben durch das umgebende Medium zugeleitet werden, oder es kann beides zugleich der Fall sein.

Wie der erste Teil der Arbeit ergab, spricht manches dafür, daß die beobachteten Erscheinungen (Formveränderungen, Ortsveränderungen und Vermehrung der diesmal untersuchten Zellen) Versuche dieser Zellen darstellen, sich den geänderten Lebensbedingungen anzupassen. Die Lostrennung von Zellen aus dem Organismus setzt dieselben unter Lebensverhältnisse, in welchen diese Zellen nur dann erhalten bleiben können, wenn sie Tätigkeiten ausüben, welche dazu fuihren, Verhältnisse wieder herzustellen, unter denen die Zellen weiter leben können. Es läßt sich dies auch so ausdrücken, die Abtrennung der Zellen, die Isolation an sich, bringt Reize für die Zellen und führt so das Geschehen herbei, welches unsre Experimente zeigten. So muissen also die bestimmenden Faktoren für dieses Geschehen in den Zellen selbst liegen, denn nur dann können sie auf die Reize in entsprechender Weise antworten.

Anderseits dürfte die Beschaffenheit des Medinms, worauf alle Versuche hinweisen, für die Frequenz der Mitosen, überhaupt für die Quantität der beoobachteten Veränderungen mitbestimmend sein. Während also die Qualitätsfaktoren im Sinne Rouxs') in den Zellen selbst liegen werden, dürfen wir dem Medium wenigstens eine Wirkung auf die Quantität des Geschehens zuschreiben.

Das Medium kann aber diese Tätigkeit wohl fast nur auslösen, es werden in ihm wesentlich nur Ausführungs- wie Realisationsfaktoren im Sinne von Roux ${ }^{1}$ ) zu suchen sein, während die Art des Geschehens bei der die Teilung bestimmenden Faktoren in den Zellen und Geweben des Explantats selbst zu suchen sind. Ob einem geeigneten Medium nicht auch eine die Qualität der Teilung etwas salterierende* Wirkung zukommen kann, bleibt weiterer Forschung vorbehalten.

Schließlich bleibt noch zu erörtern, ob nicht etwa eine in gewissem Sinne »passive Ernährung der Teile hier einen wichtigen bestimmenden oder wenigstens realisierenden Faktor für die Zellvermehrung darstellt. Es scheint dieser Fall für die Entscheidung dieser Frage besonders günstig, da hier die Nahrungszufuhr nicht

1) Roux, W., Vorträge und Aufsätze. Hft. 1. 1905. S. $137 \mathrm{ff}$. 
erst vom Parenchym des Organes ans durch Rouxs Mechanismus der Selbstbeschaffung der Nahrung unter Nervenvermittlung reguliert wird. Vielmehr liegt hier die Bestimmung der Nahrungszufuhr ganz in der Hand des Experimentators. Wenn es sich tatsächlich um eine passive Ernährung handeln würde, müßte man annehmen, daß vermehrtes, also rascheres Wachstum eintritt, wenn der Experimentator mehr Nährmaterial zugibt. Dem widerspricht aber das Ergebnis der Experimente. So konstatierte bereits Carrel, daß die Milz weit schneller wächst in dem mit $2 / 5$ destillierten Wassers verdünnten Plasma, als in dem normalen. Ich möchte darin einen Beweis für die Annahme sehen, daß es sich auch hier bei vermehrtem Wachstum nur um aktive vermehrte Assimilation und entsprechend vermehrte Aufnahme von Nährmaterial seitens des Parenchyms handelt, weil mehr Nahrung vorhanden ist, als sich das in unserm Falle der Regulationsmöglichkeit der Nahrungszufuhr beraubte Gewebe durch seine eignen Kräfte verschaffen könnte. So glaube ich, daß anch in diesem abnormen Falle noch die von Rovx ${ }^{1}$ ) vertretene und an vielen Beispielen nachgewiesene Auffassung zu Recht besteht, nach der in der Periode des vorherrschenden »funktionellen Reizlebens * (NB. unter typischen Verhältnissen, also bei dem im Organismus bestehenden Schutz vor abnormen Reizen) abnorm große Blutzufuhr, Hyperämie, für sich allein kein Wachstum mehr bewirkt. Sollten weitere Versuche ergeben, daß sich auch in Kulturen von Geweben erwachsener Säugetiere außerhalb des Organismus bei einer heute noch unbekannten Versuchsanordnung verstärktes Wachstum durch vermehrte Nahrungszufuhr allein erzielen ließe, so hätten wir darin die Aktivierung noch vorhandener vererbter Gestaltungspotenzen durch besondere Reizung zu sehen. Die vererbten Gestaltungspotenzen sind ja, wie Roux ${ }^{2}$ ) in seiner jüngsten Pablikation mitgeteilt hat, durch das ganze Leben hindurch bis zu seinem normalen Ende im Greisenalter, anfangs in der ersten Periode ursächlichen Bestimmtseins allein bestimmend, in den uibrigen von Roux nunmehr unterschiedenen drei Perioden mitbestimmend tätig, am wenigsten in der dritten Periode, in der das Vererbte sehr gegen das funktionell Bedingte zuriucktritt.

1) Roux, W., Der Kampf der Teile im Organismus. Ein Beitrag zur Vervollständigung der mechanistischen Zweckmäßigkeitslehre. Leipzig 1881. S. 138 -164, oder Ges. Abh. Bd. I. 1895. S. 301-331.

2) Roux, W., Die vier causalen Hauptperioden der Ontogenese, sowie das doppelte Bestimmtsein der organischen Gestaltungen. Mitteil. d. Naturf. Ges. zu Halle a. S. Bd. 1. 1911. 
Die bestimmenden Faktoren für die von Carret und mir außerhalb des Organismus beobachteten Wachstumsvorgänge im überlebenden Säugetiergewebe liegen demnach in den Geweben und Zellen selbst, während rom umgebenden Medinm, in welches wir die Gewebe verbringen, nur Ausführungs- oder Realisationsfaktoren ausgehen. Noch wichtiger denn als fördernde Teilursache für das Wachstum ist das Medium ans dem Grunde, weil eine ungeeignete Beschaffenheit desselben das Wachstum verhindert, indem ein ungeeignetes Medium die Zellen und Gewebe rascher oder langsamer tötet oder wenigstens so weit schädigt, daß dieselben sich nicht mehr zu teilen vermögen.

Ich komme damit zu dem Schlusse, daß die beobachteten Vorgänge der Reparation, besonders der Zellvermehrung, lediglich dem anch unter normalen Verhältnissen möglichen Gestaltungsgeschehen entsprechen, wobei aber in einigen Hinsichten ungewöhnliches Gestaltangsgeschehen erfolgt, weil neben den durch die Isolierung metazoischer Zellen aus dem Organismus geschaffenen Gestaltangsreizen (Reiz der Wundfläche) noch durch die Beschaffenheit des Mediums herangeführte Realisationsfaktoren Wirkungen ausüben. Endlich sind die beschriebenen Wachstumsvorgänge in ihrem Geschehen (nach Richtung, Zeit, Ort und Intensität) dadurch geändert, daß sie nicht Regulationseinwirkungen unterliegen, welche vom Organismus ansgehen.

Untersuchungen, wie die von E. SchULtz ${ }^{1}$ ) neuerdings begonnenen, über die Wirkungen des »Milieu «, welche ja wohl größtenteils auch in das Gebiet der Realisations- oder Ausführungsfaktoren Rouxs fallen, dürte die Explantation eine reiche Ausbente bieten, und manche der oben geschilderten verschiedenen Wirkungen des Mediums beruhen sicher auf derartigen Teilursachen.

Diese Betrachtungsweise läßt auch wohl verstehen, warum wir in den explantierten Geweben weit zahlreichere Mitosen, Zellverschiebungen usw. entstehen lassen können, als im erwachsenen Körper in der Norm vorkommen, ja daß, wie CARREL sagt, im Verlaufe einiger Tage aus einigen Zellen *eine ungeheure Anzahl von Zellen* entsteht, während dies doch im Körper beim Erwachsenen gewöhnlich nicht der Fall ist.

Wurde doch das typische Ergebnis dieses Wachstums, welches,

1) Schultz, Eugen, Prinzipien der rationellen vergleichenden Embryologie. Leipzig 1910. 
wie wir oben gesehen haben, darin besteht, die Zellen wieder allseitig in Verbindung mit Nachbarzellen zu setzen, in der Glasschale bei der bisherigen Versuchsanordnung nicht erreicht. Freilich (ich denke dabei an das radiäre Auswachsen in der Glasschale) werden diejenigen Zellen, welche zuerst an der Peripherie lagen, nach reichlichen Teilungen schließlich den geforderten AnschluB an Nachbarzellen finden, da aber das Stück inzwischen gewachsen ist und seine Peripherie vergrößert hat, wird die Zahl der Zellen, welche der fremde Reiz nunmehr trifft, noch größer geworden sein. Die CARRELsche Angabe des immer rascher zunehmenden Wachstums würde damit ganz der theoretischen Forderung entsprechen. Bei umschriebenen Defekten (Wundheilung) müßte dagegen das Wachstum mit Schluß der Wunde nachlassen.

Ein derartiges eine Zeitlang zunehmendes, nach WOLFG. OSTWALD ${ }^{1)}$ als autokatakinetisch zu charakterisierendes Wachstum sehen wir ja auch bei embryonalen Geweben. Man denke nur an das rapide Ansteigen des Wachstums in den verschiedenen Monaten der Gravidität beim Embryo, z. B. des Menschen oder eines Säugetiers. Auch rasch wachsende pathologische Neubildungen zeigen ein solches Wachstum.

In diesen beiden Fällen bestehen aber ganz andre Verhältnisse. Vor allem ist beim embryonalen Wachstum der AnschluB an Nachbargewebe gegeben und sein Fehlen kann also hier nicht als Faktor in Betracht kommen. Dies mahnt also zur Vorsicht und läßt daran denken, daB auch in unsern Experimenten noch andre Faktoren als die Isolierang in Betracht kommen können. Auch der Umstand, daß Mitosen nicht allein an den am meisten peripher liegenden Zellen, sondern auch tiefer im Gewebsstücke vorkommen, warnt davor, die Frage für gelöst zu halten.

Da wir die neue Spezialforschung erst begründen, vermögen wir die Frage noch nicht zu entscheiden, ob unsre experimentell erzeugten Kulturen vielleicht der einen oder andern der beiden zuletzt genannten Wachstumsarten nahestehen, sich also etwa embryonalen Geweben oder Tumorengewebe an die Seite stellen lassen und irgendwie mit diesen gemeinsame Faktoren besitzen.

Es wäre das Augenmerk darauf zu richten, ob die an Tumoren-

1) Ostwald, Wolfgang, Über die zeitlichen Eigenschaften des Entwicklungsvorganges. Vortr. u. Aufs. über Entwicklungspech., herausg. v. W. Roux. Hft. V. 1908. 
gewebe beobachteten Eigenschaften, so etwa die von AICHeL 1) in letzter Zeit beschriebenen Zellverschmelzangen bei experimentellen Kulturen an überlebendem Gewebe, zu sehen sind und ob sie etwa experimentell auf diesem Wege erzeugt werden können. Bis jetzt habe ich davon nichts bemerkt, wie ich iberhaupt nicht den Eindruck erhielt, daß das von mir beobachtete Wachstum geschwulstmäßigen (blastomatösen) Charakter tragen würde und auch aus diesem Grunde als atypisches Wachstum zu betrachten wäre.

Eher ließen sich Gründe anführen, welche dafür zu sprechen scheinen, daB die Zellen unsrer rasch wachsenden, experimentell erzeugten Kulturen sich embryonalen Geweben vergleichen lassen. Doch ist es auch hier in erster Linie das rasche Wachstum, welches diese Deutung zu unterstïtzen scheint, jeder histologische Beweis, daß die neugebildeten Zellen embryonalen Charakter zeigen, steht noch aus. Der Umstand, daß Carrels und meine Experimente zeigten, daß derartige Wachstumsvorgänge nicht allein bei Embryonen, sondern auch bei Geweben erwachsener Tiere hervorgerufen werden können, ohne daß ein »Embryonalwerden " des Gewebes ersichtlich wäre, ermahnt zur Vorsicht. So möchte ich annehmen, daß das Vererbte in den untersuchten Geweben sehr gegen das durch fremde Reize Bedingte zuriicktritt.

Die Entwicklung solcher Zellen und ihr Wachstum wird, immer unter der Voraussetzung, daß es uns gelingt, störende oder alterierende Einflüsse von seiten des Mediums hintanzuhalten, die einfachste $\otimes$ in Wirklichkeit « mögliche sein. Sie entspricht im Falle dieses Gelingens jener Entwicklung, welche Roux ${ }^{2}$ ) als typische Entwicklung bezeichnet, sofern die Isolation an sich nicht schon Gestaltungspotenzen aktivierend wirkt. $\mathrm{Er}$ scheidet diese streng von der »in der Mehrzahl der Fälle vorkommenden * „normalen " Entwicklung, welche durch entsprechend häufig "vorkommende a äußere Einwirkungen, also nicht allein durch die im Keimplasma vorhandenen vererbten Faktoren bedingt ist.

1. Archel, 0., Über Zellverschmelzung mit qualitativ abnormer Chromosomenverteilung als Ursache der Geschwulstbildung. Mit einem Vorwort von Prof. W. Roux. Mit $25 \mathrm{Abb}$. im Text. VIII u. $115 \mathrm{~S}$. Vorträge und Aufsätze uber Entwicklnngsmechanik der Organismen, herausgeg. v. W. Roux. Hft. 13. Leipzig 1911.

2) Rovx, W., Vortrïge und Aufsütze über Entwicklungsmechanik der Organismen, herausgeg. v. W. Roux. Hft. 1. Roux, W., Die Entwicklungsmechanik, ein neuer Zweig der biologischen Wissenschaft. Leipzig 1905. S. 28 u. 40. 
Zunächst ist aber noch sehr fraglich, ob es einmal gelingen wird, die störenden und alterierenden Einflüsse von seiten des Mediums im Experimente ganz zu beseitigen und so tatsächlich typisches Geschehen experimentell zu erzeugen. Aber auch wenn letzteres nicht gelingen sollte, haben wir es mit einem nicht der Regulation von seiten des Organismus unterstehenden Geschehen zu tun und dieses ist neben seiner eminent praktischen Bedeutung auch für den causalen Morphologen von höchstem Interesse, um so mehr, als es dem Experiment leicht zugänglich gemacht werden kann.

Freilich sind auch hier in der Regel Selbstregnlationsmechanismen im Sinne von Roux ${ }^{1)}$ denkbar, welche ron den Nachbarzellen ausgehen könnten. Bei Teilungen schließlich, welche sich an Zellen vollziehen, die fast ganz frei an exponierter Stelle in das Medium vorragen, wie ich dies zeigte, würden auch diese Mechanismen sich vereinfachen, und wir würden nur noch mit Regulationsfaktoren zu rechnen haben, welche in der Zelle selbst gelegen sind. Wir besitzen in der neuen von CARREL ausgearbeiteten Methode die Möglichkeit, Phasen des so komplizierten Geschehens der Wachstumserscheinungen des Säugetierkörpers in einer von störenden Nebenwirkungen befreiten Form zn beobachten, so rein, wie es sonst nur der Protozoenkörper gestattet, und darin besonders liegt eine hohe Bedeutung dieser Methode für die causale Morphologie.

Ich halte es deshalb für gerechtfertigt, meine experimentellen Untersuchungen über Wachstumsvorgänge an überlebenden in indifferente Medien explantierten Säugetiergeweben außerhalb des Organismus als ein Beispiel eines experimentell hervorrufbaren Gestaltungsgeschehens einfachster Form in der Reihe meiner causalmorphologischen Zellenstudien ${ }^{2}$ ) zu veröffentlichen als ein Beispiel eines der Regulation von seiten des Organismus nicht unterworfenen Gestaltungsgeschehens.

1) Roux, W, Über die Bestimmung der Hauptrichtungen des Froschembryo im Ei nnd iiber die erste Teilung des Froscheies. Breslauer ärztl. Zeitschr. 1885. Nr. 6-9. S. 34, oder Ges. Abh. Bd. II. 1895. S. 317.

2) Die I. Mitteilung ist in Medizinisch-naturwissenschaftl. Archiv. Bd. II. Hft. 1. 1908, - die II. Mitteilung im Arch. f. Entw.-Mech. Bd. 30. (Festsehrift f. Roux, I. Teil.) 1910, - die III. Mitteilung in den Beiträgen zur pathologischen Anatomie u. zur allgemeinen Pathologie. Bd. 49. 1910 erschienen. 


\section{Zusammenfassung einiger Resultate beider Teile der Arbeit.}

Die von mir angestellten Experimente haben ergeben, daß in Gewebsstiickchen von der Katze, welche dem frisch getöteten Tier entnommen und in (von demselben Tier durch Centrifugieren bei $0^{\circ} \mathrm{C}$. hergestellten) Blutplasma im Thermostat bei $37^{\circ} \mathrm{C}$. in der feuchten Kammer aufbewahrt werden, Mitosen aufgefunden werden können.

Die Mitosen waren in solchen Explantaten nach 7 stündigem Aufenthalt im Ofen zahlreicher als im frisehen Kontrollstick, wurden aber auch nach 18, 24 und mehr Stunden nachgewiesen. Das erste Auftreten neaer Mitosen an der Peripherie der Stiickchen wurde etwa 2 Stunden nach dem Einlegen in den Ofen beobachtet.

Besonders zahlreich wurden Mitosen in Milz und Knochenmark in bestimmten Wachstumszonen konstatiert, welche nahe der Peripherie des Stïckes, aber nicht ganz unmittelbar an derselben liegen. Doch wurden vereinzelte Mitosen auch an ganz exponierten Stellen bereits frei im Plasma aufgefunden.

Das frühe Auftreten der ersten und dann zahlreicherer Mitosen noch am Tage der Operation spricht dafür, daß schon während der von CARrel angenommenen Latenzperiode den dann später für das Auge und die photographische Platte wahrnehmbaren äußeren Wachstumserscheinungen eine Mitosenbildung im Innern des Stückes, vor allem in dessen peripherer Wachstumszone vorangeht, wie sie von mir beschrieben wurde.

Für weitere Untersuchungen, besonders auch für die Wundheilung, Blutbildung im Knochenmark und andre Reparations- und Wachstumserscheinungen dürfte dieses fribe Auftreten von Mitosen von nicht zu unterschätzender Bedeutung sein.

Die Regeneration der Deckepithelien an überlebenden Geweben (Trachea) erfolgt im Explantat durch aktive Wanderung der Epithelzellen. Mitosenvermehrung tritt erst später anf. Die beobachteten Bilder von auf den Defekt sich vorschiebenden Zellen stimmen mit den von den Autoren als Anfangsstadien der Reparation und Regeneration im Organismus beschriebenen Befunden vielfach überein.

Dafür, daß die Neubildung der Mitosen tatsächlich erst infolge der Explantation im überlebenden Gewebe erfolgt, sprechen folgende Befunde: 
1) Die Beschaffenheit des Mediums (Blntplasma) gewährt besonders günstige Lebensbedingungen.

2) Im Blutplasma lassen sich tatsächlich andre Lebensvorgänge (z. B. amöboide Bewegung, Zellverschiebungen) längere Zeit beobachten, als in andern Medien.

3) Die beobachteten Mitosen sind im äberlebenden, im Blutplasma befindlichen, mehrere Stunden im Ofen liegenden Stücke zahlreicher, als im frischen Kontrollstück und zeigen ein durchaus lebensfrisches Aussehen, auch in den über 24 Stunden gezüchteten Gewebsstückchen.

4) Die Anordnung der Mitosen läßt bestimmte Wachstumszonen nahe der Oberfläche des willkürlich aus dem Organismus entnommenen und dann im Ofen in Blutplasma gehaltenen Stückes erkennen.

5) Die bereits von Carrel vorgenommenen Zählungen isolierter Zellen ergaben eine tatsächliche Vermehrung der Zellen. Letzterer Befund kann nur im Zusammenhang mit den übrigen bewertet werden, da er, für sich allein betrachtet, Amitose nicht ausschließt.

Obwohl demnach die Ergebnisse der Experimente in hohem Grade dafür sprechen, daß die von mir beschriebenen Mitosen im überlebenden Gewebe entstanden sind, möchte ich doch die definitive Entscheidung der Frage weiteren Untersuchungen, an denen ich hoffe, selbst teilnehmen zu können, überlassen. Für zweifellos erwiesen halte ich aber durch meine und andrer Autoren Experimente, daß wir an ausgeschnittenen Gewebsstückchen von Säugetieren Lebensvorgänge lange Zeit hindurch beobachten können, wenn wir dieselben im BIntplasma bei $37^{\circ} \mathrm{C}$. aufbewabren. Der Lmstand, daß das Blutplasma die eingelegten Stücke so lebensfrisch erhält und ihnen ermöglicht, deutliche Lebensvorgänge zu zeigen, beweist aber noch nicht ohne weiteres, daß sich in ihm alle Lehensvorgänge und ebenso wie im Organismus vollziehen. Sollte aber das Wachstum explantierter Gewebe erwachsener Säugetiere, für dessen MIöglichkeit hente schon so vieles spricht, später noch sicberer erwiesen werden können, dann dürfen wir auch die heute von mir beschriebenen und abgebildeten Mitosen füglich als im überlebenden Gewebe entstanden anerkennen.

Jedenfalls aber verspricht die Untersuchung überlebenden Gewebes im Blutplasma bei Körpertemperatur nach der von CARREL. ausgearbeiteten Methode noch weitere Resultate. Sie ist eine wertvolle Bereicherung für die biologische Forschung und verdient Fort- 
setzuing und energische Förderung von seiten aller, welche dazu in der Lage sind.

Die neue Methode und ihre Resultate sind für die causale Forschung von Wert, weil es damit gelingt, Lebensvorgänge, vor allem Wachstums- und Regenerationsvorgänge verschiedener Art, außerhalb des Organismus in reinerer Form zu beobachten, als dies im Organismus möglich ist, da die außerhalb des Organismus geztuchteten Zellkulturen nicht den Regulationen von seiten des Organismus, seiner Organe (Nervensystem) und Säfte (Increte, Hormone usw.) unterliegen. In diesen Regulationen sieht Roux den größten Feind der causal-morphologischen Erforschung des typischen Entwicklungsgeschehens.

Während die Qualititsfaktoren in den tiberlebenden Zellen selbst liegen werden, dürfen wir in dem Medium, in welchem wir die Zellen beobachten, Realisationsfaktoren annehmen, denen wenigstens eine Wirkung auf die Quantität des Geschehens zukommt. Daß passive Ernährung der Teile einen Faktor für die Zellvermehrung bildet, lassen die vorliegenden Experimente nicht erkennen, so daß wir annehmen müssen, daß das Vererbte in den untersuchten Geweben sehr gegen das durch fremde Reize Bedingte zurícktritt.

Das excessive Wachstum der überlebenden Gewebe anßerhalb des Organismus läßt daran denken, daß die Isolierung der Zellen Störungen und Alterationen der in diesen Zellen wirkenden Faktoren hervorruft und so zur Entstehung von Reizen für das Wachstum führt, welche solange andauern, bis die durch die Organisation der Metazoenzelle geforderte Verbindung mit Nachbarzellen wieder hergestellt ist.

Dieses zunebmend sich steigernde Wachstum zeigt aber anderseits auch Ähnlichkeit mit dem Verhalten rasch wachsender Tumoren und embryonaler Gewebe. Dafür, daß es sich um ein rein geschwulstmäBiges atypisches Wachstum handeln würde, ergaben sich im übrigen keinerlei Anhaltspunkte. Wohl aber werden fernere Untersuchungen genau zu prifen und zu entscheiden haben, ob und inwieweit es sich bei dem in explantierten überlebenden Geweben beobachteten excessiven Wachstum vielleicht um eine Aktivierung der vererbten direkten Gestaltungspotenzen handelt.

Jedenfalls war es bei den bis jetzt vorliegenden Versuchen nicht möglich, die Wirkung der durch die Isolation des Gewebes und durch die Einflisse des Mediums hervorgerufenen Reize auf die Explantate auszuschalten, und es ist fraglich, ob und inwieweit uns dies ge- 
lingen wird. Es bleibt daher zweifelhaft, ob uns das Verfahren der Explantation dazu führen kann, die rein im Keimplasma determinierte, zugleich »einfachste in Wirklichkeit mögliche» Entwicklung experimentell hervorzurufen, welche von Roux als $»$ typische Entwicklung bezeichnet und streng von der durch äußere Einwirkungen »alterierten *, ev. sogar »normalen « Entwicklung unterschieden wurde.

Abgeschlossen im November 1911.

\section{Erklärung der Abbildungen.}

Tafel IX und $\mathbf{X}$.

Sämtliche Präparate sind von der Katze und wurden verschieden lange bei $37^{\circ} \mathrm{C}$. in Blutplasma im Wärmeofen gehalten (außer Fig. 5), dann in ZENKERscher Flüssigkeit konserviert, in Paraffin geschnitten und mit Hämatoxylin-Eosin gefärbt.

Fig. 1. Milz von der Katze, 5 Stunden bei $37^{\circ} \mathrm{C}$. im Blutplasma. Übersichtsbild, zeigt zahlreiche Mitosen, rechts vom Beschauer Fibrin, links Milzgewebe, bei schwacher Vergrößerung.

Fig. 2. Milz von der Katze, 2 Stunden bei $37^{\circ} \mathrm{C}$. im Blutplasma, zeigt eine Mitose bei stärkerer Vergrößerung. Die Mitose, in dem sehr diinnen Schnitt nar zum Teil getroffen, liegt an der Grenze zwischen Milzgewebe und fïdigem Fibrin des Blutplasmas.

Fig. 3. Nilz von der Katze, 7 Stunden bei $37^{\circ} \mathrm{C}$. im Blutplasma, Mitose nahe dem Rande des Stückes, aber noch ganz von Milzgerwebe umgeben.

Fig. 4. Milz von der Katze, 24 Stunden bei $37^{\circ} \mathrm{C}$. im Blutplasma. Mitose am Rande des Stückes, fast freischwimmend im Blutplasma.

Fig. 5. Milz von der Katze, 24 Stunden bei $37^{\circ} \mathrm{C}$. in Blatplasma. Große Mitose.

Fig. 6. Milz von der Katze, 24. Stunden im Eisschrank aufbewahrt, dann konserviert und gefürbt wie die übrigen Präparate. Die Figur zeigt zwei Mitosen, zwar deutlich erkennbar, aber verändert gegenüber den lebensfrischen andern Prïparaten.

Fig. 7. Knochenmark von der Katze, 7 Stunden bei $37^{\circ} \mathrm{C}$. im Blutplasma. Übersichtsbild, zeigt an zwei Stellen je zwei nebeneinander liegende Mitosen.

Fig. 8. Knochenmark von der Katze, 18 Stunden bei $37^{\circ} \mathrm{C}$. im Blutplasma, zeigt neben den ruhenden Markzellen und kernhaltigen roten Blutkörperchen drei, verschiedenen (großen und kleinen Markzellen and eosinophilen Körnchenzellen) Zellarten angehörende Mitosen.

Fig. 9. Larynxschleimhaut von der Katze, 7 Stunden bei $37^{\circ} \mathrm{C}$. im Blutplasma. Übersichtsbild. Links vom Beschaner flimmerndes Cylinderepithel, rechts die von Epithel entblößte Tunica propria, dazwischen die sich vorschiebenden niedrigen und platten Zellen. Im Plasma iber dem Epithel abgestoßene, rund gewordene Cylinderzellen und Becherzellen, untermischt mit Wanderzellen. 
Fig. 10. Larynxschleimhaut von der Katze, 7 Stunden bei $37^{\circ} \mathrm{C}$. im Blutplasma, eine Stelle des vorigen Präparats bei stärkerer Vergrößerung aus der Zone des sich über den Defekt vorschiebenden niedrigen Epithels.

Sämtliche Abbildungen wurden von der kunstgeübten Hand von Fräulein K. WANGERIN in Halle a. S. mit ZEIss-Instrumenten gezeichnet unter Benutzung eines Zeichenprismas zur Anlage, und zwar:

Fig. 1 und 7 mit Obj. homog. Imm. 1/12, Ap. 1,30, Ocul. 1, in Objekttischhühe. Tubusl. $160 \mathrm{~mm}$.

Fig. 2, 3, 4, 5, 6, 8 und 10 mit Obj. homog. Imm. $2 \mathrm{~mm}$, Comp.-Oc. 12, Höhe der Tischplatte, Tubusl. $160 \mathrm{~mm}$.

Fig. 9 Obj. D, Oc. 1, Objekttischhöhe, Tubusl. $160 \mathrm{~mm}$. 







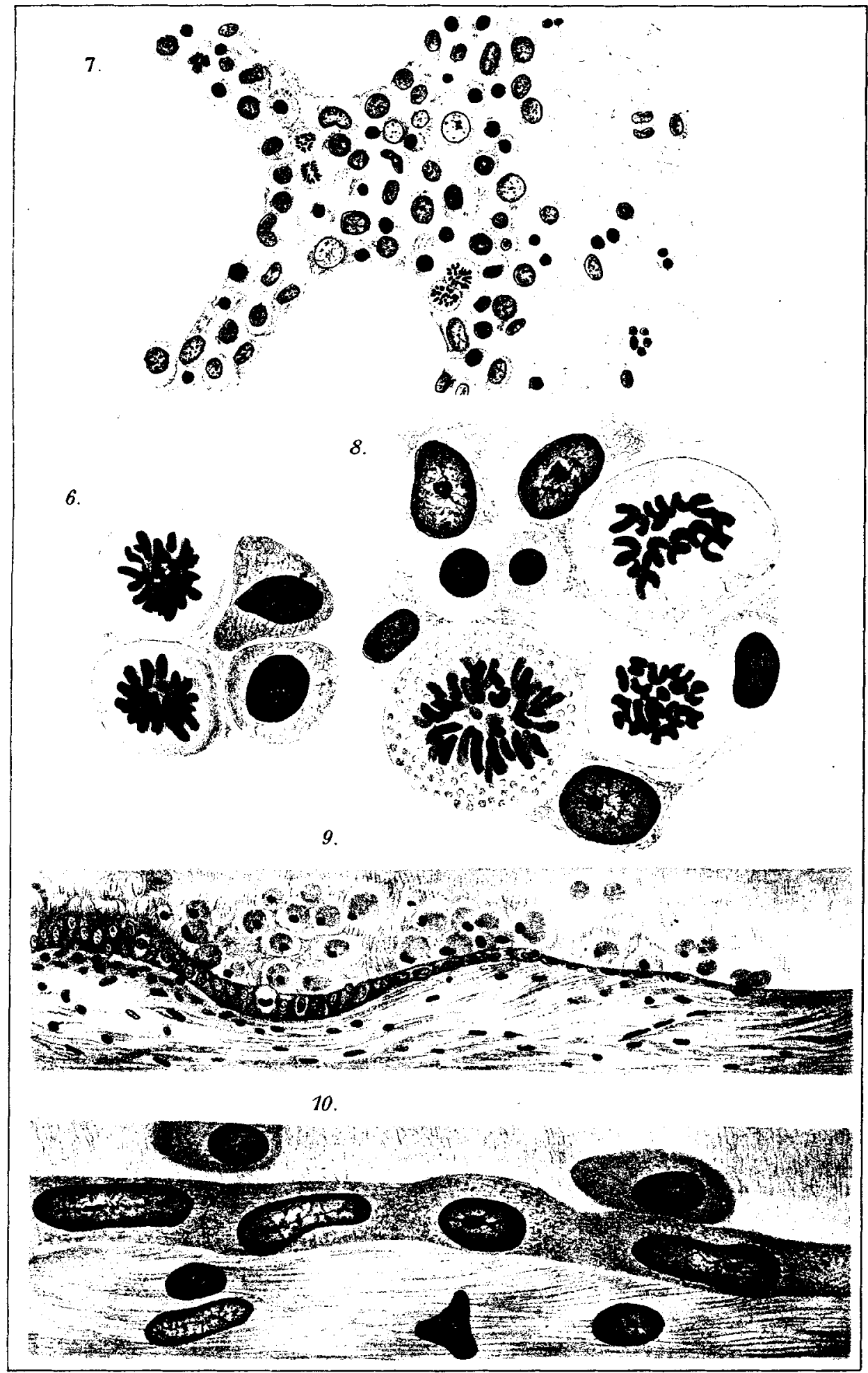

